\title{
Estudio sobre la economía circular como una alternativa sustentable frente al ocaso de la economía tradicional (segunda parte)
}

\section{Study on the Circular Economy as a Sustainable Alternative to the Decline of the Traditional Economy (Second Part)}

Adriana Norma Martínez* https://orcid.org/0000-0001-8962-2743 Adriana Margarita Porcelli** https://orcid.org/0000-0002-5192-5893 http://dx.doi.org/10.21503/lex.v17i23.1679

* Abogada, escribana, posgraduada en Derecho del Turismo UBA. Magíster en Ambiente Humano. UNLZ. Profesora adjunta regular Departamento de la Facultad de Derecho Universidad de Buenos Aires. Jefa de la División Derecho. Profesora asociada ordinaria Universidad Nacional de Luján. Departamento de Ciencias Sociales. Argentina. Correo electrónico: info@anmart.com.ar

** Abogada UBA. Magíster en Relaciones Internacionales Universidad Maimónides. Diplomada en Derechos Económicos, Sociales y Culturales UNPSJB. Profesora adjunta ordinaria, División Derecho Universidad, Nacional de Luján. Departamento de Ciencias Sociales, Argentina.

Correo electrónico: adporcelli@yahoo.com.ar

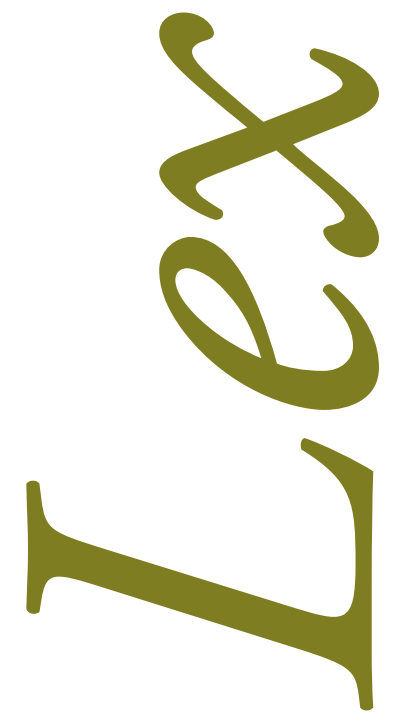




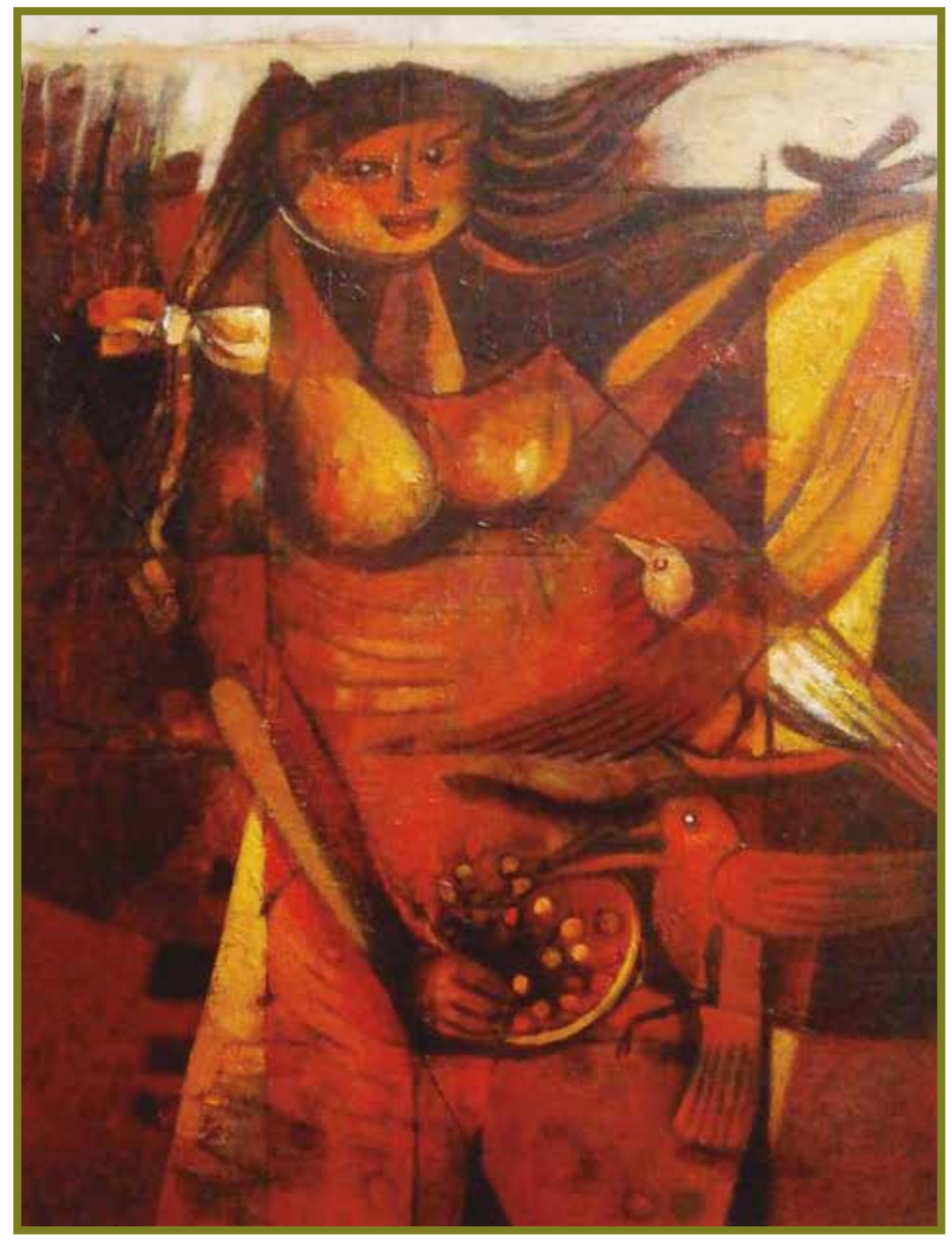

Palomas en rojo. Óleo $60 \times 50 \mathrm{~cm}$. Agustín Aquino Mejías (pintor peruano). 


\section{RESUMEN}

El presente trabajo forma parte de una investigación que analiza, entre otros, los impactos ambientales de la obsolescencia programada, la economía verde y específicamente el modelo económico alternativo denominado economía circular, desarrollada en el Departamento de Ciencias Sociales de la Universidad Nacional de Luján. Dicha investigación tiene por objeto analizar, en primer lugar, si la economía circular es una alternativa fiable y plausible para desarrollar un nuevo modelo que permita propiciar una cultura altamente sustentable y respetuosa del ambiente; sus pilares, así como sus ventajas y desventajas y las más destacadas prácticas empresariales y gubernamentales, a ese respecto, en el mundo y en Argentina, y, en segundo lugar, su recepción en las diferentes legislaciones y en la normativa voluntaria. Debido a la extensión del tema, el mismo se expone en dos partes y el presente artículo constituye la segunda y última parte consistente en el análisis de las diferentes legislaciones que han optado por la economía circular y la normativa voluntaria.

Palabras clave: economía circular, reutilización, reparación, reciclaje, residuos.

\section{ABSTRACT}

This work is part of a research project that analyses, among others, the environmental impacts of planned obsolescence, the green economy and specifically the alternative economic model called circular economy, carried out at the Department of Social Sciences of the National University of Luján. The purpose of this investigation is to analyze, firstly, if the circular economy is a reliable and plausible alternative to develop a new model to promote a highly sustainable and environmentally friendly culture, its pillars, the most outstanding business and government practices, in this respect, in the world and in Argentine, and, secondly, its reception in the different legislations and standarization. Due to the extension of the topic, it is presented in two parts and the present article constitutes the second and last part consisting in the analysis of the different legislations that have opted for circular economy and standarization.

Key words: circular economy, reuse, repair, recycling, waste. 


\section{INTRODUCCIÓN}

En la primera parte del trabajo se identificaron las principales limitaciones del modelo económico actual, se desarrollaron detenidamente las principales escuelas de pensamiento, los conceptos y principios teórico-técnicos específicos de la economía circular, sus pilares, así como sus ventajas y desventajas y las más destacadas prácticas empresariales y gubernamentales, a ese respecto, en el mundo y en Argentina. ${ }^{1}$

En el presente artículo, utilizando el método deductivo y analítico, se profundizará en el análisis de las legislaciones a nivel internacional, regional y nacional y en la normativa voluntaria que receptaron el mencionado modelo circular.

La metodología adoptada se relaciona con la observación documental y el relevamiento del contenido en base a la triangulación de la información de las distintas fuentes proveniente de todas las áreas comprendidas. Consiste en el análisis y sistematización de la legislación existente sobre el tema.

\section{RECEPCIÓN DE LOS PRINCIPIOS DE LA ECONOMÍA CIRCULAR EN LAS DIFERENTES LEGISLACIONES}

\section{Normativa Comunitaria: Unión Europea}

En diciembre de 2014, la Comisión Europea (CE) decidió retirar una propuesta legislativa pendiente sobre residuos, y se comprometió a presentar, a finales de 2015 , un nuevo paquete de medidas referido a todo el ciclo económico, no solo a la reducción de residuos. Después de un año de arduo trabajo, el 2 de diciembre de 2015, adoptó, en Bruselas, un ambicioso paquete de propuestas para convertir la economía europea en una más circular. La propia

La primera parte de la investigación se puede consultar en Adriana Norma Martínez y Adriana Margarita Porcelli, "Estudio sobre la economía circular como una alternativa sustentable frente al ocaso de la economía tradicional (primera parte)". Lex 22, 16, ańo XVI (2018): 301-334, ISSN 2313-1861, http://dx.doi.org/10.21503/lex.v16i22.1659 https://doi.org/10.21503/lex.v16i22.1659 
Comisión explicaba que las acciones incluidas en aquel paquete de medidas contribuirían a "cerrar el círculo" de los ciclos de vida de los productos a través de un mayor reciclado y reutilización, y aportarían beneficios tanto ambientales como económicos. La finalidad consiste en obtener el máximo valor y uso de todas las materias primas, productos y residuos, fomentar el ahorro energético y reducir las emisiones de gases de efecto invernadero. La aproximación hacia una economía circular constituye el núcleo del Programa de Eficiencia en el Empleo de los Recursos, establecido en el marco de la Estrategia Europa $2020 .^{2}$

Entre las medidas más importantes figuran:

a) La financiación de más de 650 millones de euros con cargo a Horizonte 2020 (el programa de financiación de la investigación e innovación de la Unión) y de 5500 millones de euros con cargo a los Fondos Estructurales y de Inversión Europeos (Fondos EIE).

b) La adopción de medidas para reducir el derroche de alimentos.

c) Una indicación de fechas mejorada y herramientas que permitan alcanzar la meta 12.3 del objetivo 12 de los Objetivos de Desarrollo Sostenible (ODS), consistente en reducir a la mitad el desperdicio de alimentos a más tardar en 2030.

d) La elaboración de normas de calidad para las materias primas secundarias.

e) La adopción de medidas en el Plan de Trabajo sobre Diseño Ecológico para 20152017 tendientes a promover la reparabilidad, durabilidad y reciclabilidad de los productos, además de la eficiencia energética.

f) Una revisión del Reglamento sobre abonos y reforzar el papel de los bionutrientes.

g) Una estrategia para el plástico en la economía circular, que aborde los problemas de la reciclabilidad, la biodegradabilidad, la presencia de sustancias peligrosas en los plásticos y dé cumplimiento al objetivo 14 de los ODS, vale decir, reducir significativamente los desechos marinos.

h) Una serie de acciones sobre la reutilización del agua, incluida una propuesta legislativa relativa a los requisitos mínimos para la reutilización de las aguas residuales.

i) Una propuesta legislativa para reformar la Directiva Marco de Residuos, la Directiva de Envases, la Directiva de Vertederos y en menor medida otras Directivas de Residuos. Entre los elementos clave de esta propuesta sobre residuos figuran los siguientes objeti-

2 Adriana Norma Martínez y Adriana Margarita Porcelli, "El desafío del cambio económico: la economía circular y su excepción en las diferentes legislaciones y en la normativa voluntaria", Pensar en Derecho, n. ${ }^{\circ} 13$, año V (2018): 129-181, ISSN 2314-0194. 
vos comunes a 2030: reciclar el $65 \%$ de los residuos municipales y el $75 \%$ de los residuos de envases, reducir la eliminación a un máximo del $10 \%$ de todos los residuos en vertedero, prohibir el depósito en vertedero de los residuos recogidos por separado, desalentar la eliminación en vertedero, promover la reutilización y la simbiosis industrial, convirtiendo los subproductos de una industria de materias primas en otra y apoyar a los regímenes de recuperación y reciclado incentivando productos más ecológicos.

La consecución de los nuevos objetivos en materia de residuos permitirá crear 580000 nuevos puestos de trabajo, en comparación con los resultados actuales. La limitación de residuos, el diseño ecológico, la reutilización y medidas similares podrían aportar a las empresas un ahorro neto de 600 mil millones de euros, o el $8 \%$ del volumen de negocios anual, reduciendo al mismo tiempo las emisiones anuales totales de gases de efecto invernadero entre 2 al $4 \%$. En los sectores de la reutilización, la refabricación y la reparación, por ejemplo, el coste de la remanufactura de teléfonos móviles podría reducirse a la mitad si fueran más fáciles de desmontar. Si se recogiera el 95 \% de los teléfonos móviles, podrían obtenerse ahorros en los costes del material de fabricación superiores a los mil millones de euros. En igual sentido, el paso del reciclado a la renovación de los vehículos industriales ligeros podría ahorrar 6400 millones de euros al año (alrededor del $15 \%$ del presupuesto de materiales) en insumos de materiales y 140 millones de euros en costes energéticos, además de reducir las emisiones de gases de efecto invernadero en 6,3 millones de toneladas. ${ }^{3}$

Con respecto a las energías renovables, en los últimos años se observan igualmente importantes progresos. Sin embargo, sigue siendo altamente dependiente de las energías fósiles, responsables del $80 \%$ de sus emisiones, evitando que pueda alcanzar sus objetivos de reducción para 2050. En consecuencia, en enero de 2014, la Comisión propuso un nuevo Paquete Clima y Energía para 2030, aplicable a partir de 2021. Consiste en la reducción de un $40 \%$ de emisiones de GEI con respecto a los niveles de 1990, la utilización de al menos un $27 \%$ de energías renovables para el conjunto de la Unión y un aumento de al menos un $27 \%$ en eficiencia energética para el conjunto de la Unión. ${ }^{4}$

Sin embargo, no todas las opiniones son favorables. La organización ecologista Amigos de la Tierra considera esta nueva propuesta como poco ambiciosa. Señala que las medidas adoptadas están muy lejos de alcanzar una economía circular. En su opinión, los porcentajes

3 Comisión Europea, "Comunicado de prensa. Cerrar el círculo: la Comisión adopta un ambicioso paquete de nuevas medidas sobre la economía circular para impulsar la competitividad, crear empleo y generar crecimiento sostenible" (IP/15/6203. Bruselas: Comisión Europea, 2015).

4 Beatriz Pérez de las Heras, "La gestión eficiente de recursos en la Unión Europea: alcance e impacto de la normativa europea para una economía más sostenible y circular", Revista de Derecho Comunitario Europeo n. ${ }^{\circ} 55$ (2016): 781-817. doi: http://dx.doi.org/10.18042/cepc/rdce.55.01

https://doi.org/10.18042/cepc/rdce.55.01 
de reciclaje y preparación para la reutilización han sido reducidos del 70 al $65 \%$, mientras que se ha eliminado el porcentaje del $30 \%$ de reducción de desperdicio alimentario y se ha omitido la obligación de separar la fracción orgánica de los residuos en origen. Decisiones todas ellas que, alertan, denotan la falta de compromiso por avanzar hacia una verdadera economía circular. ${ }^{5}$

El documento intitulado "Comunicación de la Comisión al Parlamento Europeo, al Consejo, al Comité Económico y Social Europeo y al Comité de las Regiones. Cerrar el círculo: un plan de acción de la UE para la economía circular", del 2 de diciembre de 2015, destaca que ese Plan de Acción contribuirá a la consecución de los ODS antes de 2030. En particular, del objetivo 12 con vistas a garantizar modelos sostenibles de consumo y producción y de la Alianza del G-7 sobre la eficiencia de los recursos. A posteriori, analiza cómo un mejor diseńo puede hacer que los productos sean más duraderos o más fáciles de reparar, actualizar o reelaborar. A tales efectos, se centró en los futuros requisitos de diseño de productos en el marco de la Directiva sobre diseño ecológico. Hasta la fecha, esos requisitos se han orientado hacia la eficiencia energética. La Comisión señala que apoyará la reparabilidad, durabilidad y reciclabilidad en los requisitos de los productos en los próximos planes de trabajo por los que se aplique la Directiva sobre diseño ecológico; preparará un programa de ensayos independiente en el marco de Horizonte 2020 para detectar problemas relacionados con una posible obsolescencia programada; propondrá requisitos para desmontar, reutilizar y reciclar las pantallas electrónicas; propondrá la diferenciación de las contribuciones financieras abonadas por los productores en el régimen de responsabilidad ampliada del productor; propondrá recompensas para la reutilización a nivel nacional en la propuesta revisada sobre los residuos; adoptará medidas sobre la contratación pública ecológica (CPE); incluirá orientaciones sobre mejores prácticas en la gestión de los residuos y la eficiencia en el uso de los recursos sobre las mejores técnicas disponibles (BREF); ofrecerá orientaciones y promoverá las mejores prácticas en relación con los residuos mineros.

Entre las iniciativas previstas para apoyar la reparabilidad de los productos y combatir la obsolescencia programada, se pueden mencionar los trabajos sobre las medidas de ejecución del diseño ecológico revisadas (a partir de 2016); la normalización sobre eficiencia de los materiales dentro del diseño ecológico incluirá trabajos sobre normas que faciliten la reparación (a más tardar en 2019); la exploración de la posibilidad de imponer requisitos horizontales relativos a la presencia de información sobre reparaciones en el marco de la Directiva sobre diseño ecológico y ,también, la elaboración de un programa de ensayos independiente, en el marco de Horizonte 2020, para contribuir a identificar las cuestiones relacionadas con la po-

5 Laura Martín, “Europa da carpetazo a la economía de 'usar y tirar' y apuesta por la economía circular”, Compromiso Empresarial (2016), acceso el 15 de diciembre de 2018, http:/www.compromisoempresarial.com/ rsc/2016/01/europa-da-carpetazo-a-la-economia-de-usar-y-tirar-y-apuesta-por-la-economia-circular/ 
sible obsolescencia programada. Además, la Comisión emprenderá las tareas de elaboración de las normas de calidad aplicables a las materias primas secundarias allí donde sean necesarias (en particular, respecto de los plásticos); adoptará medidas para facilitar el transporte legal de residuos entre los Estados miembros, junto con nuevas medidas encaminadas a reducir el número de traslados ilegales; revisará la normativa europea relativa a los abonos; tomará medidas para facilitar la reutilización del agua, efectuará análisis y propondrá opciones sobre la interfaz entre la legislación en materia de sustancias químicas, productos y residuos. Considera que cuando los residuos no se puedan evitar ni reciclar, es preferible en la mayoría de los casos, tanto en términos ambientales como económicos, recuperar su contenido energético en lugar de eliminarlos en vertederos. A tal efecto, la Comisión adoptará una iniciativa sobre «producción de energía a partir de residuos» en el marco de la Unión de la Energía.

En estrecha cooperación con la Agencia Europea de Medio Ambiente (AEMA) y tras consultar a los Estados miembros, elaborará un marco de seguimiento para la economía circular. El programa de trabajo de Horizonte 2020 incluye una iniciativa importante sobre «Industria 2020 en la economía circular», con una dotación de más de 650 millones de euros. En la actualidad, la utilización del plástico está creciendo, pero la eficiencia del reciclado se va quedando atrás. Se recicla menos del $25 \%$ de los residuos plásticos recogidos, y alrededor del $50 \%$ van al vertedero. Por tanto, adoptará una estrategia sobre el plástico que abordará cuestiones como la reciclabilidad, la biodegradabilidad, la presencia de sustancias peligrosas en los plásticos y los desechos marinos; propondrá un objetivo más ambicioso para el reciclado de envases de plástico en la propuesta legislativa revisada sobre los residuos. Junto con los Estados miembros, la Comisión adoptará medidas para clarificar la legislación europea relativa a los residuos, los alimentos y los piensos a fin de facilitar la redistribución de alimentos comestibles y seguros a las personas necesitadas. Y cuando resulte segura, la utilización de antiguos alimentos como recurso para la alimentación animal. De este modo se garantizará que esos alimentos no se consideren «residuos» en ningún lugar de la Unión y puedan, por tanto, utilizarse como recurso para producir piensos animales. También elaborará, en cooperación con los Estados miembros y las partes interesadas, directrices relativas a la donación de alimentos en la Unión para donantes y bancos de alimentos, adoptará una serie de medidas para promover la recuperación de materias primas críticas, propondrá un Reglamento revisado sobre fertilizantes y un marco de seguimiento simple y eficaz para controlar los principales elementos del Plan de Acción. ${ }^{6}$

El 26 de enero de 2017, transcurrido un año de la adopción de su paquete de medidas sobre la economía circular, la Comisión presentó un Reporte de Implementación y un Anexo

6 Comisión Europea, "Comunicación de la Comisión al Parlamento Europeo, al Consejo, al Comité Económico y Social Europeo y al Comité de las Regiones. Cerrar el círculo: un plan de acción de la UE para la economía circular" (COM [2015] 614 final. Bruselas: Comisión Europea, 2015). 
de Resumen de Acciones que resaltan los progresos que se han logrado hasta ese momento, así como, las nuevas iniciativas que serán lanzadas en el corto plazo para avanzar hacia un modelo circular. En dicho reporte se señala que el 30 de noviembre de 2016 la Comisión adoptó el Ecodesign Working Plan 2016-2019, vale decir el Plan de Trabajo del Ecodiseño 2016-2019, como parte del Clean Energy for All Europeans Package — Paquete de Energía Limpia para todos los Europeos— que en lo fundamental se centra en la eficiencia de recursos más allá del ahorro energético. Introduce nuevos criterios como la durabilidad, reparabilidad y reciclaje. Asimismo, se resumen las medidas existentes en ecodiseńo y ecoetiquetas, sobre todo en dispositivos electrónicos y anuncia una Guía para la Transición hacia una Economía Circular en referencia a las Mejores Técnicas Disponibles (MTD) para varios sectores industriales. Dentro de los residuos y materias primas secundarias, el desperdicio alimentario representa una de las grandes prioridades de la Comisión. Para avanzar en esta materia, se ha puesto en marcha, el 1 de agosto de 2016, una Plataforma sobre la Prevención del Desperdicio Alimentario, desde la que se está trabajando en el desarrollo de una metodología europea para medir el desperdicio alimentario y en la definición de unas directrices para facilitar las donaciones de alimentos. En esta categoría también se han considerado los fertilizantes y se ha propuesto el dictado de un Reglamento que permita crear un mercado único para aquellos producidos a base de materias primas secundarias.

El nuevo Reglamento propuesto establece normas comunes sobre la conversión de biorresiduos en materias primas que pueden utilizarse para fabricar fertilizantes, define concretos requisitos de seguridad, calidad y etiquetado que deben cumplir todos los productos fertilizantes para ser objeto de libre comercio en toda la Unión. Lo novedoso es que el fabricante podrá, en función de su estrategia comercial y del tipo de producto, optar por colocarle el marcado, haciendo posible su libre comercio en el mercado interior conforme a normas europeas comunes, o venderlo con arreglo a normas nacionales basadas en el reconocimiento mutuo en el mercado único. ${ }^{7}$

El paquete de medidas adoptado también incluyó una Propuesta de modificación de la Directiva 2011/65/EU sobre restricciones a la utilización de determinadas sustancias peligrosas en aparatos eléctricos y electrónicos (Directiva RUSP). Las modificaciones propuestas facilitarán las operaciones del mercado de segunda mano (por ejemplo, la reventa) y la reparación de aparatos eléctricos y electrónicos. Se calcula que con esas medidas se evitará la generación de más de 3000 toneladas de residuos peligrosos al ańo y se ahorrarán energía y materias primas. En lo referido a las acciones de prevención o reciclado de plásticos, la Comisión publicó el Plan de Trabajo para el Desarrollo de una Estrategia Europea sobre plásticos

\footnotetext{
7 Sara García García, "Economía circular: la Unión Europea impulsa reformas sobre la base de un tema crucial, la gestión de residuos, con el fin de alcanzar mejoras económicas y medioambientales", Revista Actualidad Jurídica Ambiental, n. ${ }^{\circ}$ 57 (2016): 1-11 ISSN: 1989-5666 NIPO: 721-15-001-4.
} 
contextualizada en una economía circular. El Plan consiste, fundamentalmente, en desvincular la producción de plásticos de las materias primas fósiles y reducir las emisiones de gases de efecto invernadero en el ciclo de vida de estos materiales; mejorar el impacto económico, la calidad, la utilización del reciclaje y reutilización de plásticos y reducir la deposición de residuos plásticos en el ambiente. Junto con el Reporte reseñado, la Comisión anunció el lanzamiento de dos nuevas plataformas: la plataforma europea de financiación de economía circular, coordinada por la Comisión Europea y el Banco Europeo de Inversión, que ofrece apoyo a los proyectos de economía circular y la plataforma europea de grupos de interés en economía circular, que se estructurará sobre la base de tres pilares principales: compartir mejores prácticas, intercambio de información entre los principales grupos de interés y diálogo institucional. La Comisión Europea y el Comité Económico y Social Europeo lanzaron la plataforma de agentes europeos de la economía circular (\#CEStakeholderEU) como una «red de redes» destinada a reforzar la cooperación entre las redes de agentes y a facilitar el intercambio de experiencias y de prácticas recomendadas sobre la economía circular. El 31 de mayo de 2017, Business Europe lanzó la plataforma de la industria de la economía circular europea (European Circular Economy Industry Platform, www.circulary.eu) para exponer la labor de las pequeńas y medianas empresas y de la industria en favor de la economía circular. Otro ejemplo es la plataforma de contratación sostenible (Sustainable Procurement Platform) gestionada por International Council for Local Environmental Initiatives - ICLEI- Gobiernos Locales por la Sustentabilidad. Proporciona noticias, casos prácticos, información sobre próximos eventos, orientación y otros datos sobre la contratación sostenible en todo el mundo. ${ }^{8}$

Por su parte, el programa Horizonte 2020 ha dedicado en una de sus convocatorias - denominada Industria 2020 en la Economía Circular - a financiar proyectos innovadores de economía circular y competitividad industrial. Además, asumió el compromiso, para el 2018, a continuar cumpliendo lo previsto en el plan de acción, presentando una estrategia sobre los plásticos, un marco de seguimiento para la economía circular y una propuesta dirigida a fomentar la reutilización del agua.?

Junto con este informe, la Comisión presentó una nueva Comunicación sobre la transformación de los residuos en energía y su lugar en la economía circular, más allá de la incineración de residuos. El objetivo principal consiste en garantizar que la recuperación de la energía procedente de residuos cumpla con los objetivos del Plan de Acción de la Economía Circular. En relación con esto, el Comité Económico y Social Europeo (CESE) emitió un

8 Para más información, véase: “Sostener el impulso de la transición a la economía circular", Revista Medio Ambiente para los Europeos, $\mathrm{n}^{\circ} 64$ (2017): 10.

9 Comisión Europea. "Comunicado de prensa Economía circular: la Comisión cumple sus promesas, ofrece orientaciones sobre la valorización energética a partir de residuos y trabaja con el BEI para impulsar la inversión” (IP/17/104. Bruselas: Comisión Europea, 2017). 
Dictamen sobre el contenido de la Comunicación de la Comisión al Parlamento titulada "El papel de la transformación de los residuos en energía". Para el Comité, la transición hacia la ansiada economía circular se ve muchas veces dificultada por la creación de obstáculos y barreras, agravada por las continuas subvenciones injustificadas que recibe el sector de los combustibles fósiles. Todo ello debe acompañarse por un tratamiento y una gestión adecuados, lo que supone un abandono progresivo de la incineración de residuos y a cambio utilizar un método alternativo. Respecto de este tema, señala que será esencial el desarrollo de políticas de disuasión, en un caso, e incentivación, en otro, tales como la introducción de impuestos; la eliminación progresiva de los regímenes de ayuda; o el establecimiento de una moratoria sobre las nuevas instalaciones y el desmantelamiento de las antiguas. ${ }^{10}$

Por su parte, el 30 de noviembre de 2017 el Comité Europeo de las Regiones (CoR) adoptó el Dictamen denominado "El papel de la transformación de los residuos en energía en la economía circular". Si bien el texto defiende que la valorización energética desempeña un rol importante en el desarrollo de una economía circular, los líderes locales recuerdan que la jerarquía de residuos debe ser el principio rector en la gestión de los residuos. En la cumbre de la jerarquía se encuentra la prevención de residuos, seguida por la reutilización de productos, el reciclaje, la valorización energética y el vertido como el escenario óptimo. Las ciudades y regiones recomiendan a los Estados con poca o ninguna capacidad de incineración, no desarrollar la recuperación de energía a menos que sea bajo una planificación muy cuidadosa, y priorizar en su lugar programas de recolección selectiva y reciclaje. Las regiones y ciudades europeas reiteran la necesidad de crear mercados estables para los productos y materiales basados en materias primas secundarias. Igualmente, los miembros del Comité apoyan los traslados de residuos entre Estados miembros para fines de recuperación de energía si ello evita o reduce el vertido o ayuda a hacer un mejor uso de las instalaciones existentes. ${ }^{11}$

El estudio "Situación y potencial de valorización energética directa de residuos. Estudio Técnico PER -Plan Estatal de Residuos- 2011-2020” realizado en 2011 por el Instituto para la Diversificación y Ahorro de Energía (IDAE) concluye que aun contando con elevadas tasas de reciclado y tratando buena parte de la fracción orgánica mediante compostaje seguiría existiendo un resto importante cuyo destino, hoy por hoy, no podría ser otro que su eliminación en vertedero o el tratamiento térmico. La propia Organización Mundial de la Salud, en un informe titulado "Las dioxinas y sus efectos en la salud humana", afirma que, dado que la combustión es incompleta, la incineración descontrolada de desechos (sólidos y hospitalarios)

10 Comité Económico y Social Europeo, "Dictamen del Comité Económico y Social Europeo Comunicación de la Comisión al Parlamento Europeo, al Consejo, al Comité Económico y Social Europeo y al Comité de las Regiones 'El papel de la transformación de los residuos en energía”, Diario Oficial de la Unión Europea, 13 oct. 2017. C 345/102-109 [COM (2017) 34 final].

11 Comité Europeo de las Regiones, "Dictamen El papel de la transformación de los residuos en energía en la economía circular" (COR-2017-01982-00-00-AC-TRA). 
suele ser la causa más grave de la liberación de dioxinas al ambiente, pero que existe tecnología que permite la incineración controlada de desechos con bajas emisiones. En el pasado, las plantas de incineración constituían una fuente importante de emisiones de dioxinas, ya que carecían de filtros, pero puede afirmarse que esta realidad ha cambiado. Por eso, una parte de la doctrina prefiere hablar de termovalorización, lo que implica, al menos en la Unión Europea, que los procesos cumplen con estrictas normas de emisiones y de eficiencia energética. ${ }^{12}$

El 31 de octubre de 2017, la organización Zero Waste Europe publicó un nuevo informe titulado "Deliverorpay, orhowwasteincineration causes recyclingtoslowdown", en el que previene contra la prohibición del vertido y aboga por la utilización de instrumentos más efectivos para la reducción de los residuos y avanzar hacia una economía circular. El documento sostiene que la mayoría de las jurisdicciones que han prohibido el uso de vertederos han visto multiplicarse en exceso las plantas de producción de energía a partir de residuos. Continúa analizando que en los siete países europeos donde se ha establecido la prohibición del vertido el resultado, el resultado ha sido que se desvíen más residuos hacia la incineración que hacia el reciclaje. Es el caso de Países Bajos y Alemania. En el caso de Austria y Noruega, el reciclado incluso ha disminuido y en Dinamarca, la prohibición del vertido ha supuesto un aumento de la incineración acompañada de un incremento de la generación de residuos del 37,5\%. El texto también destaca que una política de vertido cero que no tienda a la reutilización y la reducción de residuos permite a los países continuar con una economía lineal, aumentando la generación de residuos en la medida en que estos se puedan quemar o reciclar. En el citado informe se comparan dos casos diferentes: el de Copenhague (Dinamarca), donde existe una política de vertido cero, y el de la provincia de Treviso (Italia), con "una estrategia de cero residuos real". La capital danesa tiene casi seis veces más residuos que Treviso, donde no existe la prohibición del vertido, pero sí una política de cero residuos para todo tipo de desechos. Con el objetivo de avanzar hacia una economía circular, esta organización recomienda adoptar medidas que considera más eficaces que la prohibición del vertido para favorecer la prevención, la preparación para la reutilización y el reciclaje. ${ }^{13}$

En enero de 2018, la Comisión Europea publicó una Comunicación que recoge la estrategia sobre plásticos, acompañada de un marco de seguimiento de la economía circular y un documento de trabajo. La estrategia sobre plásticos busca proteger el medio ambiente, fomentar el crecimiento y la innovación y se estima que crearán empleos y nuevas oportunidades de inversión. Bajo los nuevos planes, todos los envases de plásticos en el mercado de

12 Gabriel Real Ferrer, "Residuos y sostenibilidad. El modelo europeo", Revista Aranzadi de Derecho Ambiental, n. ${ }^{\circ} 35$ (2016): 57-87.

13 Sara Muznik, "Deliver or pay", or how waste incineration causes recycling to slow down", Zero Waste Europe (2017), acceso el 16 de diciembre de 2018, https://zerowasteeurope.eu/2017/10/deliver-pay-waste-incineration-causes-recycling-slow/ 
la Unión serán reciclables en 2030, se reducirá el consumo de plásticos de un solo uso y se limitará el uso de microplásticos. Con esta nueva estrategia, la Unión Europea procura convertir el reciclaje en un negocio rentable, reducir los residuos de plástico, evitar la basura en el mar, impulsar la inversión e innovación y promover un cambio global. En el marco de dicha estrategia, la Comisión Europea propuso nuevas normas para los diez productos plásticos de un solo uso más comunes en las playas y mares de Europa. En caso de aprobarse, las nuevas normas introducirán la prohibición del plástico en determinados productos, la reducción del consumo, obligaciones de los productores, objetivos de recogida, requisitos de etiquetado y medidas de sensibilización.

Por su parte, el marco de seguimiento de la Comisión es una herramienta clave para medir el progreso y cubrir las diferentes fases de la economía circular tanto en la Unión como en los Estados miembros. Su objetivo consiste en mostrar si las iniciativas políticas existentes son eficaces para la obtención de los resultados esperados y la identificación de las áreas donde se necesita insistir en las mejoras. El marco se estructura en cuatro grandes áreas: producción y consumo (se centra en la autosuficiencia de materias primas, la contratación pública verde, la generación de residuos y el desperdicio alimentario), gestión de residuos (se centra en la proporción de residuos que se reciclan en relación con el conjunto de la economía), materias primas secundarias (mide la contribución de los materiales reciclados a la demanda de materias primas y su comercio) y competitividad e innovación (inversiones privadas, el empleo y el valor agregado, así como las patentes relacionadas con los sectores de la economía circular). A modo de síntesis se puede destacar que la generación de residuos urbanos per cápita en la Unión se redujo un $8 \%$ entre 2006 y 2016. No obstante, se observan grandes variaciones, ya que la generación de residuos urbanos continúa aumentando en varios Estados miembros. La reducción de los residuos alimentarios ofrece un enorme potencial de ahorro. Se producen residuos alimentarios a lo largo de toda la cadena de valor, en consecuencia, tales residuos son especialmente difíciles de cuantificar. Según las primeras estimaciones, los residuos alimentarios se redujeron de 81 a 76 millones de toneladas (es decir, en torno a un $7 \%$ ) entre 2012 y 2014, lo que equivale a una disminución de 161 a 149 kg per cápita. Entre 2008 y 2016, las tasas de reciclaje de los residuos urbanos aumentaron de un $37 \%$ a un $46 \%$. Cinco Estados miembros reciclan más de la mitad de sus residuos urbanos, mientras que otros países se van acercando al objetivo de reciclaje del $65 \%$ para 2030 propuesto por la Comisión. Pero, cinco Estados miembros se encuentran todavía por debajo del $25 \%$. Entre 2008 y 2015, también aumentaron las tasas de reciclaje de los residuos de envases, de un $62 \%$ a un $66 \%$. En el caso de los envases de plástico, la tasa media de reciclaje es considerablemente inferior (el 40 $\%$ ), a pesar de las mejoras en los últimos ańos. En 2016, el reciclaje de biorresiduos urbanos era de $79 \mathrm{~kg}$ per cápita, esto es, un incremento del $23 \%$ con respecto a 2007. En cuanto al reciclaje de los residuos de aparatos eléctricos y electrónicos (RAEE), los datos muestran que el nivel de recogida y reciclaje varía considerablemente entre los Estados miembros y que hay 
un gran potencial para la mejora de la eficiencia en el uso de los recursos y la reducción de la recogida, el tratamiento y el traslado ilegal. En 2015, tan solo cuatro Estados miembros reciclaron más de la mitad de los aparatos eléctricos y electrónicos comercializados. Por último, en cuanto a los residuos de la construcción y la demolición, veinte Estados miembros han informado que ya han alcanzado el objetivo de valorización del $70 \%$ establecido para 2020. Sin embargo, cabe señalar que el objetivo incluye la operación del relleno, una práctica que no conlleva el mantenimiento del valor de los materiales en la economía y que, por lo tanto, no contribuye a una economía circular. Con respecto a las materias primas secundarias, la contribución de los materiales reciclados a la satisfacción de la demanda de materias primas es aún pequeña o incluso insignificante. Ello puede deberse a que su reciclaje no resulta rentable, a que no se dispone de la tecnología para reciclarlos o a que los materiales están incorporados en productos que se mantienen en uso durante un largo tiempo (por ejemplo, las tierras raras que se usan en las turbinas eólicas). Por otra parte, el indicador sobre el comercio de residuos reciclables pone de manifiesto que la Unión es un exportador neto de varios de los principales flujos de residuos reciclables, como plásticos, papel y cartón, hierro y acero, cobre, aluminio y níquel. Su comercio en el seno de la Unión aumentó considerablemente entre 2004 y 2016, lo que ha permitido a los agentes económicos cosechar los beneficios del mercado interior de materias primas secundarias. ${ }^{14}$

En lo referido a las ciudades de los Estados Miembros de la Unión, en septiembre del año 2015, el Ayuntamiento de París realizó una petición denominada "Call of cities for circular economy" - "Llamamiento a las ciudades a favor de la Economía Circular" — con la finalidad de promover modelos basados en la economía circular entre las entidades locales. ${ }^{15}$

A este respecto, se ha atendido a que, conforme los datos de Naciones Unidas, el $70 \%$ de la población del planeta vivirá en las ciudades para el 2050. Por tanto, los municipios de Amsterdam, Bruselas, Copenhague, Lisboa, Londres, Milán y Roma ya la han firmado y en concreto asumieron el compromiso de reducir los impactos ambientales y a desarrollar políticas a favor de la economía circular mediante acciones tendientes al vertido cero, el reciclaje (en especial de biorresiduos), la reducción de los desechos (fundamentalmente de alimentos), el ecodiseño, preparación para la reutilización y el reciclaje. El 15 de marzo del 2017, continuando con este modelo, diferentes localidades suscribieron la "Declaración de Sevilla: el compromiso de las ciudades por la Economía Circular”. Con el objetivo de establecer un modelo de desarrollo sostenible, inclusivo y resiliente, el instrumento propone la reducción del

${ }^{14}$ Comisión Europea, “Comunicación de la Comisión al Parlamento Europeo, al Consejo, al Comité Económico y Social Europeo y al Comité de las Regiones. Sobre un marco de seguimiento para la economía circular” [COM (2018) 29 final. Estrasburgo: Comisión Europea, 2018].

15 Francia, Ayuntamiento de París, Call of cities for circular economy, París (2015), acceso el 8 de noviembre de 2018, http:// www.acrplus.org/images/news/20150915-EtatsGeneraux-call_of_cities_for_circular_economy.pdf 
consumo de los recursos naturales, el impulso del reciclaje y la reutilización. Han apoyado la declaración los municipios de Sevilla, Córdoba, Granada, Jaén, Vigo, Toledo, Tarragona, Logroño, Badajoz, Coslada, Fuenlabrada, Bustarviejo, Gavá o Granollers. Y ya son diversas las ciudades que están generando iniciativas exitosas. La ciudad inglesa de Peterborough, al norte de Londres, ha liderado este cambio al poner en marcha una ambiciosa e innovadora estrategia de economía circular, con la que pretende gestionar de forma eficiente sus numerosos recursos para que esta ciudad funcione como un organismo vivo. Plantea siete pasos para cerrar el círculo (las 7 R): repensar la manera en la que se gastan recursos, rediseñar los productos para que puedan desmontarse, reutilizar los artículos (economía colaborativa), reparar (la obsolescencia programada es uno de los grandes enemigos de la economía circular), remanufacturar, reciclar y recuperar. Y espera convertirse en la primera ciudad 100\% circular del Reino Unido. ${ }^{16}$

\section{Normativa Nacional}

\subsection{España}

La Fundación COTEC publicó, el 10 de febrero de 2017, el primer informe sobre economía circular en Espańa. El documento, realizado con la colaboración de la Cátedra UNESCO de Sostenibilidad de la Universidad Politécnica de Catalunya (UPC), la Asociación Internacional Reciclar Ciudad (RECNET) y la Asociación para la Sostenibilidad y el Progreso de las Sociedades (ASYPS), ofrece un completo análisis académico de la situación. El informe resalta que España está centrando la mayoría de los esfuerzos en un aspecto de la economía circular, en la política de residuos. No solo en lo referente a gestión, sino también hace hincapié en la reparabilidad de los productos y la lucha contra la obsolescencia programada, así como la conversión de los residuos en recursos. El Plan Estatal Marco de Gestión de Residuos (PEMAR) 2016-2022 tiene el objetivo final de convertirlo en una sociedad eficiente en el uso de los recursos, que avance hacia una economía circular, lo cual se ve reflejado en la aplicación del principio de jerarquía de residuos establecido en la normativa comunitaria. También destaca la Estrategia española de Bioeconomía Horizonte 2030, la que incorpora como sectores objeto de atención al agroalimentario, el de los bioproductos industriales, el de la bioenergía obtenida de la biomasa o el de los servicios asociados a los entornos rurales. Sin embargo, aún quedan por desarrollar programas o acciones para reducir el desperdicio de alimentos, quizás en espera del desarrollo de normativa y metodología común de la Unión al respecto. ${ }^{17}$

Alineados con el impulso europeo hacia la economía circular, el 18 de septiembre de 2017, los Ministerios de Agricultura y Pesca, Alimentación y Medio Ambiente, y de Eco-

16 Carlos Fresneda, “Las siete 'R' de la ciudad circular”. El Mundo, España (2017), acceso el 15 de diciembre de 2018, https:/www.elmundo.es/ciencia-y-salud/ciencia/2017/07/31/597e21d3268e3eea578b457b.html

17 Fundación Cotec, Situación y evolución de la economía circular en España (Madrid: Fundación Cotec, 2017), 46-48. 
nomía, Industria y Competitividad y el comisario europeo de Medio Ambiente suscribieron el "Pacto por una economía circular: El compromiso de los agentes económicos y sociales 2018-2020”, que junto a las 53 entidades que se han adherido, busca impulsar la transición hacia una economía circular, baja en emisiones. En el acto de firma del mismo, la ministra de Agricultura explicó que el Gobierno prepara una estrategia para la economía circular que se abrirá a la participación pública y espera pueda implantarse en 2018. Esta estrategia, según precisó, estará orientada con el Paquete de Acción de Economía Circular que presentó la Unión Europea (explicada ut supra). De esta manera, tanto España como la Unión Europea se comprometieron a impulsar la transición a una economía circular mediante un conjunto de acciones concretas, tales como: reducir el uso de los recursos naturales no renovables, reutilizando los residuos como materias primas secundarias; impulsar el análisis del ciclo de vida de los productos y la incorporación de criterios de ecodiseño; la aplicación efectiva del principio de jerarquía de los residuos; incrementar las formas innovadoras de consumo sostenible y los servicios digitales; promover el uso de la ecoetiqueta y difundir la importancia de avanzar desde la economía lineal hacia una economía circular. ${ }^{18}$ Entre ellas, se destaca la creación, por el Real Decreto 6/2018, vigente desde el 23 de enero de 2018, de la Comisión Interministerial para la incorporación de criterios ecológicos en la contratación pública dependiente del Ministerio de Agricultura y Pesca, Alimentación y Medio Ambiente. La norma destaca, en sus fundamentos, la finalización del Plan de Contratación Pública Verde, refiere a la Estrategia Española de Responsabilidad Social de las empresas y a la consideración de la Huella de Carbono en la contratación pública. Establece que su finalidad es garantizar la coordinación de la Administración General del Estado y sus Organismos Públicos en la incorporación y el uso de criterios ecológicos en la contratación pública — artículo 2 (fines) — y detalla sus funciones en el artículo 4 (funciones). En la actualidad, se encuentra aún pendiente de entrada en vigor la Ley 9/2017 de Contratos del Sector Público, por la que se incorporan al ordenamiento jurídico español las Directivas del Parlamento Europeo y del Consejo 2014/23/UE y 2014/24/ UE, de 26 de febrero de $2014 .^{19}$

En lo referido a las comunidades autónomas españolas, se observa que, si bien todas presentan planes y programas de residuos, solo en el País Vasco o Euskadi, Cataluña y recientemente en Castilla-La Mancha, existe específicamente una estrategia en materia de Economía Circular. También es importante citar la Ley Andaluza de Bioeconomía, que trata uno de los principales aspectos descritos en el paquete de Economía Circular de la Unión.

18 Para más información: Espańa, Ministerio de Agricultura y Pesca, Alimentación y Medio Ambiente, "Pacto por una economía circular: el compromiso de los agentes económicos y sociales 2018-2020", Mapama (2017), acceso el 8 de abril de 2018, http://www.mapama.gob.es/directo/PactoEconomiaCircular.pdf

19 Para profundizar en el tema, véase: España, Ministerio de la Presidencia y para las Administraciones Territoriales, "Real Decreto 6/2018, de 12 de enero, por el que se crea la Comisión Interministerial para la incorporación de criterios ecológicos en la contratación pública”, Boletín Oficial del Estado, n. ${ }^{\circ}$ 19, sec. 1 (22 de enero de 2018). 
El Consejo de Ministros aprobó, el 18 de mayo de 2018, a propuesta del Ministerio de Agricultura y Pesca, Alimentación y Medio Ambiente (MAPAMA), el Real Decreto sobre reducción del consumo de bolsas de plástico. La norma crea el Registro de Productores, con el objetivo de reducir el consumo de bolsas de plástico ligeras y crear un registro para obtener información sobre las bolsas de plástico puestas en el mercado en el país. En virtud de este Real Decreto, a partir del 1 de julio de 2018 se deben cobrar todas las bolsas, a excepción de las muy ligeras que se suministran como envase primario para alimentos a granel y las bolsas gruesas que tengan un porcentaje de plástico reciclado igual o superior al $70 \%$, para fomentar el uso de plástico reciclado. Además, desde el 1 de enero de 2021 se prohíben las bolsas de plástico ligeras y muy ligeras y las gruesas deberán contener al menos un $50 \%$ de plástico reciclado, para promover el uso de plástico reciclado. Asimismo, prevé la realización de campañas de sensibilización, que informen sobre el contenedor en el que deben depositarse los residuos de las bolsas de plástico, compostables y no compostables y sobre los efectos nocivos que supone el abandono de los plásticos en el ambiente. Este Real Decreto supone el primer paso de la futura hoja de ruta para los plásticos en Espańa, la que tendrá por objeto evitar su abandono, reducir la generación de residuos de plástico, aumentar la tasa de reciclaje y su reutilización y fomentar la generación de plástico reciclado de calidad. Otro de los grandes retos del Ministerio es el cumplimiento de los objetivos de reciclado para los residuos municipales, por ello, y tras abordarlo con las administraciones autonómicas y locales, el 18 de mayo salió a información pública una modificación puntual de la Ley de Residuos, por la que se establece la obligación de recoger en los municipios de más de 5000 habitantes de forma separada, la fracción orgánica de los residuos municipales antes del 31 de diciembre de $2020 .^{20}$

\subsubsection{Comunidades Autónomas Españolas}

\section{a) Castilla - La Mancha}

Los incendios en la planta de reciclaje industrial de Chiloeches (Guadalajara) y en el vertedero ilegal de neumáticos de Seseña (Toledo) en marcaron un punto de inflexión en la política de gestión de residuos del Gobierno de Castilla-La Mancha. Estos hechos dieron lugar a la redacción de una nueva Ley de Economía Circular cuyo borrador, prácticamente finalizado, se encuentra a la espera de aportes cuando pase a información pública. En Castilla-La Mancha no hay precedentes, la normativa es novedosa, es más, es pionera en el Estado español, ya que será la primera comunidad que aborda la regulación de este tipo de economía con rango de ley. Trata de llevar al ordenamiento jurídico los principios de la Comunicación de la Comisión al Parlamento Europeo en el documento "Cerrar el círculo: un plan de acción

20 Fundación para la Economía Circular, "España aprueba el Real Decreto sobre reducción del consumo de las bolsas de plástico", Boletín De la cuna a la cuna (2018), acceso el 4 de junio de 2018, http://economiacircular.org/NL/nt/210518/ noticia3.html 
de la UE para la economía circular”. La nueva ley procura incluir los principios de la economía circular en el sistema productivo de la región, y proporcionar soluciones a problemas tales como la gestión de los recursos naturales (agua, suelo, servicios ecosistémicos, diversidad biológica o energía), el proceso de producción, el consumo — aquí entraría en juego la economía colaborativa- y la gestión de residuos. Precisamente, este último aspecto es uno de los más importantes, ya que introduce el mercado de materias primas, plásticos, residuos de alimentos, residuos de construcción y demolición, biomasa y biomateriales. La nueva norma establece multas, fianzas o "fiscalidad ambiental", que se aplicarán a empresas y particulares contaminantes y que ya se contemplan en el Plan Regional de Gestión de Residuos. Se estima que se podrá recaudar hasta 15 millones de euros en multas y fianzas a empresas contaminantes, que conformarán una "tasa verde" para realizar políticas ambientales. Asimismo, al hilo de esta normativa, el Gobierno castellano-manchego procura minimizar los riesgos para la salud humana y el ambiente, impulsar la competitividad y el crecimiento económico, crear empleo, favorecer el desarrollo sostenible, contribuir a la lucha contra el cambio climático y la promoción de la economía hipocarbónica. A este respecto, también se encuentra en preparación un programa de promoción para el desarrollo de una economía rural hipocarbónica, que integra las medidas establecidas en el Plan de Desarrollo Rural 2014-2020 y en la Estrategia Regional frente al Cambio Climático. Junto con todo ello la idea es "desmaterializar la economía", desvinculando el crecimiento económico del consumo de recursos. En lo atinente a residuos, la Ley de Economía Circular busca la convergencia hacia el "mínimo vertido", eliminando progresivamente el depósito controlado de residuos. ${ }^{21}$

\section{b) Castilla y León}

En cumplimiento con los objetivos fijados en la Agenda 2030 y en la Estrategia Europea 2020, el 18 de enero de 2018, la Junta de Castilla y León aprobó la Estrategia de Eficiencia Energética Castilla y León 2020. Su objetivo es superar el objetivo fijado por la Unión Europea del incremento del $20 \%$ de la eficiencia energética, lo que representará en 2020, cifrar el ahorro energético, respecto a 1990, en el 32,45\%, lo que en valor absoluto implicará un ahorro energético acumulado entre los años 2016 y 2020 de 757300 tep en energía final. ${ }^{22}$ El objetivo es ambicioso y su logro implicará reducir las emisiones de dióxido de carbono en un 30,24\% respecto al año 1990, lo que en valor absoluto significará dejar de emitir, respecto a 2007, 2 522400 toneladas del mismo, superando en 10,24 puntos porcentuales el objetivo fijado de

21 Alicia Avilés Pozo, "Castilla - La Mancha tomará la delantera con la primera Ley de Economía Circular de España”, eldiario.es, Castilla-La Mancha, 1 de nov. de 2017, acceso el 1 de febrero de 2019, http://www.eldiario.es/clm/Castilla-La-Mancha-Economia-Circular-Espana_0_703429894.html

22 La tonelada equivalente de petróleo (tep, en inglés toe) es una unidad de energía, equivale a la energía que rinde una tonelada de petróleo y es una de las unidades grandes de energía que sirve también de parámetro de los niveles de emisión de dióxido de carbono a la atmósfera que se generan al quemar diversos combustibles, como carbón, plástico, es decir, que el petróleo se considera como patrón de medida, como la unidad. Un tep = 11 678,8kWh. 
la Estrategia Europa 2020. La inversión total estimada de la Estrategia es de 799,1 millones de euros, de los que 547,9 (68,6 \%) será inversión privada y 251,2 (31,4\%) será pública y se identifican 7 sectores estratégicos: industrial, edificación, transportes, servicios públicos, administración autonómica, I+D+i en eficiencia energética y formación, comunicación y difusión. ${ }^{23}$

\section{c) Cataluña}

En Cataluńa, fue aprobada por el ACUERDO GOV/73/2015, de 26 de mayo del ańo 2015, la Estrategia de Impulso a la Economía Verde y a la Economía Circular, que promueve la sostenibilidad como eje estratégico para alcanzar la recuperación económica, mejorar la competitividad, crear empleo y reducir los riesgos ambientales. Este objetivo y actuación ejecutiva responden a los diferentes mandatos y recomendaciones internacionales relativas a la necesidad de impulsar un modelo de economía verde y circular para alcanzar un crecimiento económico sostenible a lo largo del tiempo, basado en la innovación y la competitividad. Esta necesidad se identifica en primer lugar en el "Informe sobre la economía verde", publicado en 2011 por el Programa de las Naciones Unidas para el Medio Ambiente (PNUMA) y la suscribe la comunidad internacional en la Conferencia de Naciones Unidas para el Desarrollo Sostenible de Río+20 (2012). El Consejo Europeo, por su parte, adoptó en 2010 la "Estrategia Europa 2020" (E2020), en la cual la economía verde se plantea como la política que ha de ayudar a alcanzar un nivel económico óptimo, mediante el impulso de la competitividad, la productividad y el crecimiento. En coherencia, el Gobierno catalán aprobó en sesión de 10 de abril de 2012, el documento de base de la "Estrategia Cataluña 2020", donde se identifica la economía verde como uno de los ámbitos prioritarios para mejorar la competitividad y la ocupación. Esta estrategia es, por lo tanto, una herramienta que contextualiza el concepto de economía verde y circular en Cataluña y, a la vez, se convierte en una hoja de ruta de carácter estratégico que establece las líneas de trabajo a desarrollar a medio plazo para impulsar este modelo económico en Espańa. Entre sus objetivos, se destacan: alinear la estrategia del Gobierno en materia de competitividad de acuerdo con las líneas de crecimiento inteligente, sostenible e integrador que postula la Unión; comunicar los esfuerzos que en materia de economía verde y circular está desarrollando el Gobierno local; incrementar la capacidad de transformación hacia una economía verde y circular. En cuanto a los ámbitos claves que impulsa la normativa, se identifican: la generación de demanda y creación de mercados, mejorar el acceso a la financiación, promover la innovación y desarrollo, impulsar la internacionalización y fomentar el empleo. ${ }^{24}$

23 Comunidad de Castilla y León, Consejería de Economía y Hacienda, "Acuerdo 2/2018, de 18 de enero, de la Junta de Castilla y León, por el que se aprueba la Estrategia de Eficiencia Energética de Castilla y León 2020”, Boletín Oficial de Castilla y León, n. ${ }^{\circ} 16$ (23 de enero de 2018).

24 El programa se puede consultar en: Govern de la Generalitat de Catalunya, "Impuls a l'Economia Verda I a l'Economia Circular", Diari Oficial de la Generalitat de Catalunya, n. ${ }^{\circ}$ 6881, 28 de mayo de 2015, CVE-DOGC-A-15146102-2015. 


\section{d) País Vasco o Euskadi}

Euskadi cuenta con una importante serie de instrumentos que facilitan la transición hacia la economía circular, tales como la compra y contratación pública verde, la tracción ambiental sobre cadena de suministro a través del Basque Ecodesign Center, el desarrollo de estándares técnicos y ambientales, las autorizaciones y licencias ambientales y las inspecciones administrativas. Esta variada gama de instrumentos apoyan a las empresas que se deciden por negocios circulares e incluyen ayudas a proyectos de ecoinnovación, proyectos demostración, subvenciones y también deducciones fiscales del impuesto de sociedades por inversión en tecnologías limpias. En este marco, Ihobe -Sociedad Pública de Gestión Ambiental del País Vasco puso en marcha en 2014, la Iniciativa de "Proyectos Demostración en Economía Circular" alineada con las actuaciones previstas en el "Plan de Prevención y Gestión de Residuos 2020" y en el Proyecto clave "Fabricación Verde" del Programa Marco Ambiental 2020, iniciativa que se repitió durante los ejercicios 2015 y 2016. El 1 de febrero, Ihobe publicó el informe con los resultados de las tres convocatorias (2014-2015-2016), destacando que se han apoyado 36 proyectos de diferentes características. Los proyectos seleccionados prevén obtener, en caso de éxito, un potencial de ahorro de materiales de 276000 toneladas de materiales/ año, 38,7 mil millones de euros al ańo de facturación y la creación de 156 nuevos empleos. ${ }^{25}$

\section{e) Extremadura}

El 22 de mayo de 2017, la Junta de Extremadura, junto con representantes de agentes sociales y económicos, suscribió un acuerdo para la construcción y puesta en marcha de una “Estrategia de Economía Verde y Circular para Extremadura. Extremadura 2030". El acuerdo se inscribe en el Marco Regional de Impulso a la Economía Verde y Circular de Extremadura cuyo objetivo principal consiste en convertir a la región en un referente internacional en economía verde y economía circular para el 2030. Considerando a la economía circular como la base de la economía verde, como su ADN (porque transforma los procesos productivos lineales de la economía industrial en procesos circulares, emulando a la naturaleza), estructura un nuevo modelo que supone para Extremadura la oportunidad de convertir la debilidad que finca en la falta de industrialización en una ventaja en torno a la calidad y cantidad de los recursos naturales de los que dispone. En especial, destaca la importancia del turismo de naturaleza, del valor de la biodiversidad, de la producción de energías limpias y renovables, de la calidad o de la cantidad de agua de los embalses y ríos. En este Marco Estratégico se plantean 3 niveles de actuación, 4 programas (sobre participación masiva ciudadana, concertación social y acuerdo político, sobre capacitación ciudadana en liderazgos verdes destinados al empleo y al emprendimiento, sobre investigación en economía verde, bioeconomía y economía

25 Sociedad Pública de Gestión Ambiental, Iniciativas empresariales de economía circular en el País Vasco. Descripción de 36 proyectos (Bilbao: Sociedad Pública de Gestión Ambiental, 2017), 9-14. 
circular y sobre identificación del potencial de la economía verde y circular en Extremadura) 30 proyectos-guías y más de 300 actuaciones. ${ }^{26}$

\subsection{China}

En las dos últimas décadas, China ha sido uno de los países con mayor crecimiento económico, con más altos niveles de contaminación y el primer país en emisiones de dióxido de carbono. Ante esta realidad, las autoridades ambientales chinas adoptaron el concepto de economía circular e implementaron los principios de "reducción, reutilización y reciclaje" en la producción, distribución y consumo, dentro de tres niveles básicos de acción. En el primer nivel, la empresa individual debe ser eficiente reduciendo el consumo de recursos y emisiones contaminantes y de residuos, reutilizando los recursos y reciclando los subproductos. En el segundo, el de los parques eco-industriales e industrias en grupo, es necesario reutilizar y reciclar los recursos, de modo tal que circulen íntegramente dentro del sistema de producción local. Por último, en el tercer nivel, se deben integrar los sistemas de producción y consumo en las distintas regiones chinas, pudiendo circular los recursos entre las industrias y los sistemas urbanos. Este último nivel requiere el desarrollo municipal o regional de sistemas de recolección, almacenaje, procesado y distribución para cada producto. En los tres niveles se exige producción más limpia, y facilidades públicas para poder realizar el concepto de economía circular. Por todo ello, en enero de 2009 entró en vigor la Ley de Economía Circular. La norma refuerza y amplía los principios básicos de "reducir, reutilizar y reciclar" ya establecidos en leyes ambientales anteriores, tales como la Ley de Conservación de Energía, la Ley de Aguas o la Ley de Producción Limpia. Pero, a diferencia de las anteriores, esta nueva ley se centra exclusivamente en estos principios, dotándolos por primera vez de una definición detallada y un desarrollo pormenorizado de cada uno de ellos.

El artículo 2, incluido en el Capítulo I (Principios Generales), define el término economía circular como la que adopta los principios de reducción, reutilización y reciclaje en los procesos de producción, circulación y consumo. Coloca en la cabeza del gobierno y del mercado el desarrollo de esta economía, así como señala que las empresas la llevan a cabo con la participación de la población (artículo 3). Las empresas e instituciones públicas deberán reducir el consumo de recursos, de la producción, el vertido de desechos y mejorar la reutilización y reciclaje de estos (artículo 9). El capítulo II (Reglas de Administración Básicas) especifica con mayor detalle los requisitos que deberán contener los planes de desarrollo de esta ley (artículo 12). Un precepto de gran importancia es introducido por el artículo 15. Consiste en la obligación de las autoridades chinas de desarrollar un Catálogo de Productos y Envases sujetos a

26 Junta de Extremadura, "Marco Regional de Impulso a la Economía Verde y Circular en Extremadura", Extremadura (2017), acceso el 3 de diciembre de 2018, http://extremadura2030.com/wp-content/uploads/2017/03/marco_070617_ v.f_sin-anexos.pdf 
reciclaje obligatorio. Esta tiene por correlato la obligación de los productores de reciclarlos, siempre que sea técnica o económicamente posible, y, en caso de no serlo, transformarlos en materia inocua para el ambiente. A esos efectos, la norma faculta a los productores a delegar contractualmente estas responsabilidades en sus distribuidores u otras organizaciones (presumiblemente empresas de reciclaje), sin aclarar si el productor será el responsable primario en caso de que el reciclaje no se produzca. Corresponde poner de relieve que las industrias de alto consumo de energía y agua son reguladas en cuanto a la conservación de energía y de agua por la Ley de Conservación de Energía y supervisadas por el departamento administrativo de economía circular (artículo 16). Asimismo, cabe destacar que por primera vez se introduce el Departamento de Desarrollo de Economía Circular (luego se reitera en toda la Ley) bajo el Consejo de Estado. La ley dedica los capítulos III y IV a analizar con más profundidad los tres principios básicos de reducción, reutilización y reciclaje. En este aspecto, en el artículo 18 se establece otro catálogo, esta vez para técnicas, equipo, materiales y productos fomentados (en especial el uso de agua reciclada), restringidos (el petróleo) o eliminados, estos últimos no podrán ser producidos, importados, vendidos o usados. En el artículo 27 se restringe o prohíbe el uso de agua corriente para limpieza de vías urbanas, plantación agrícola o paisajismo. El capítulo IV obliga a las empresas e industrias, en la medida de lo posible, a la utilización y reciclaje total de sus desechos, y prevé un sistema de intercambio de información sobre desechos industriales. De este modo, los desechos que no puedan ser reutilizados por una empresa puedan ser utilizados por otras (artículo 36), fomentándose un mercado colaborativo de salida e intercambio de desechos de todo tipo (artículo 37). Por último, los capítulos V y VI, respectivamente, hacen referencia a los incentivos para el fomento del desarrollo de la economía circular y las responsabilidades legales (penales y multas) derivadas del incumplimiento de la Ley. ${ }^{27}$

Desde la entrada en vigor de la ley, la Comisión Nacional de Desarrollo y Reforma y el Ministerio de Protección Ambiental han promovido modelos de simbiosis industrial, como en la Zona Desarrollo Económico y Tecnológico de Rizhao. Asimismo, se han otorgado exenciones fiscales a las empresas en el sector de la reutilización y se han promulgado objetivos para las industrias del carbón, acero, electrónica, química y petroquímica. La economía circular fue actualizada con una estrategia de desarrollo nacional en el XII Plan Quinquenal ${ }^{28}$ (2011-15). Los objetivos incluyeron la reutilización del $72 \%$ de los residuos sólidos industriales para 2015 y el aumento de la productividad de los recursos (producción económica por unidad de recursos utilizados) en un $15 \%$. El plan presentó una triple estrategia de 10-100-1000:

27 Leticia Hernández y José Luis Ruiz Galán, "Nueva Ley de Economía Circular”, Roca Junyent Shanghai Office (2008), acceso el 14 de diciembre de 2018, https://www.casaasia.es/pdf/220954813PM1233593293716.pdf

28 Cada cinco años, en la República Popular de China se renuevan los objetivos del país en el ámbito social y económico mediante la publicación de los denominados Planes Quinquenales, que establecen nuevos retos en el ámbito nacional e internacional como el eje directriz de desarrollo del país a corto plazo. 
- 10 programas principales enfocados en el reciclaje de desechos industriales, la conversión de parques industriales, la refabricación, la minería urbana y el desarrollo de sistemas de recolección y reciclaje de desechos.

- 100 ciudades verdes como Suzhou y Guangzhou.

- 1000 parques industriales en todo el país.

En el año 2012, la Comisión Nacional de Desarrollo y Reforma y el Ministerio de Finanzas solicitaron que el $50 \%$ de los parques industriales nacionales y el $30 \%$ de los provinciales completaran las iniciativas de transformación de la economía circular para 2015, con el objetivo de lograr una descarga de contaminantes cercana a cero.

El Nuevo Distrito de Suzhou constituye un ejemplo de iniciativas en parques de simbiosis industrial. Las placas de circuitos fabricadas a mano a partir de restos de cobre de otras industrias más pesadas, se destacan entre las prácticas circulares. La administración del parque industrial de Suzhou identificó el reciclaje y la recirculación de recursos metálicos como el oro y el cobre dentro de la cadena de suministro de tableros de circuitos impresos. Las empresas de residuos electrónicos recuperan el cobre y el agua generados por el procesamiento de tableros de circuitos. También se puede mencionar, como otros ejemplos, que un productor de caolín (un tipo de arcilla) utiliza los residuos de la minería como insumos para la producción de ácido sulfúrico y materiales de construcción; un fabricante de papel utiliza los residuos de amoníaco de una compañía química en su proceso de desulfuración y se produce el reciclaje del agua industrial. ${ }^{29}$

En sintonía, a fines de 2014, se habían construido 10,5 mil millones de $\mathrm{m}^{2}$ de edificios de bajo consumo en zonas urbanas, lo que constituye aproximadamente el $38 \%$ de la superficie total de los edificios de viviendas urbanas y la producción de vehículos de nueva energía se incrementó 45 veces entre 2011 y $2015 .^{30}$

No obstante, todos estos progresos resultaron insuficientes para transformar la economía de China, país que consume la mayor cantidad de recursos del planeta, pero que también produce la mayor cantidad de desechos. A este respecto, Chen Oinghua, profesor del Instituto de Medio Ambiente de la Universidad de Fujian, lamentó que, al año 2015, la tasa de reciclaje de plásticos de China no alcanzó el $30 \% .{ }^{31}$ Ante ello, en octubre de 2015, el Comité Central

29 John Mathews y Hao Tan, “Lessons from China”, Nature, n. 531 (2016): 440-443. PMid:27008954

30 Estos datos se pueden consultar en: United Nations Environment Programme, "Forests to cover one quarter of China in country's bid to build eco-civilization”, UNEP (2016), acceso el 7 de agosto de 2018, https://www.unenvironment.org/ news-and-stories/news/forests-cover-one-quarter-china-countrys-bid-build-eco-civilization

31 "China quiere ponerse al nivel de la UE en desarrollo de la economía circular", La Vanguardia, 23 de noviembre de 2016, acceso el 29 de mayo de 2018, http://www.lavanguardia.com/vida/20161123/412109862646/china-quiere-ponerse-alnivel-de-la-ue-en-desarrollo-de-la-economia-circular.html 
del Partido Comunista Chino, en quinta sesión plenaria, aprobó el XIII Plan Quinquenal (2016-2020), que amplía, detalla y cuantifica alguno de los objetivos ambientales. Desde la óptica de desarrollo sostenible, en lo que interesa a este trabajo, lo destacable radica en la apuesta de Xi Jinping por desarrollar una economía verde. Los objetivos son ciertamente desafiantes para China, que ha basado el desarrollo de su industria y la generación de energía en el consumo del carbón, causando graves problemas de contaminación. ${ }^{32}$

El plan incluye las siguientes propuestas:

- Mejorar la asignación de recursos incrementando el valor de la producción de la industria de reciclaje en tres billones de yuanes, lo que supone un aumento del $67 \%$ frente al año 2015 y la relación de reciclaje de los desechos principales deberá alcanzar el 54,6\% para el 2020.

- Fortalecer las medidas ambientales y desarrollar el concepto de "ciudades verdes".

- Fomentar la producción no residual y facilitar la financiación a empresas que optimicen su plan de gestión ambiental.

- Incentivar el consumo de energía ambientalmente responsable por parte de la sociedad.

- Controlar y fomentar la producción limpia y tecnológicamente avanzada.

- Asegurar el seguimiento de políticas relacionadas con la contaminación del agua, aire y tierra.

- Mejorar la protección ambiental fomentando el desarrollo de las nuevas energías y redes eléctricas inteligentes e impulsar el transporte eléctrico.

- Optimizar el tratamiento del agua y realizar 20 proyectos de conservación.

- Ascender, para el 2020 a 70 \% la proporción de los cursos de agua apta para el consumo humano y pesca y a $5 \%$ para la agricultura.

- Reducir el consumo de energía primaria a menos de 5000 millones de toneladas de carbón para el 2020. Esto último supone que el incremento anual deberá reducirse desde el 3,6 \% registrado en el periodo 2011-2015 hasta un 2,5\%.

- Disminuir el consumo de energía por unidad de PBI al $15 \%$ con base 2015.

32 Águeda Parra Pérez, "XIII Plan Quinquenal de China: desafíos geopolíticos para la gobernanza mundial”, Instituto Español de Estudios Estratégicos (2016), acceso el 9 de diciembre de 2018, http://www.ieee.es/Galerias/fichero/docs_opinion/2016/DIEEEO96-2016_PlanQuinquenal_China_AguedaParra.pdf 
- Reducir las emisiones de dióxido de carbono por unidad de PBI al 40-45 \% con base 2015.

- Reducir el consumo de agua en un $35 \%$ con base 2013.

- Fabricación y venta de 5 millones de vehículos alimentados con las nuevas energías. ${ }^{33}$

El plan también prevé, en materia de generación de energía renovable, la creación de más de 13 millones de empleos y una inversión de 2500 millones de yuanes hasta el 2020, de cuales 1000 se destinarán a proyectos de energía solar, 700 a eólica, 500 a hidroeléctrica y mareomotriz y 300 a geotermia. Corresponde destacar que, como lo venían haciendo los planes anteriores, el instrumento incluye la energía nuclear dentro de las energías renovables. China cuenta con 35 reactores de energía nuclear en operación, 21 se encuentran en construcción y se prevé incrementar la capacidad hasta llegar a 58 GW en 2020, 150 GW en $2030^{34}$.

El Programa de Naciones Unidas para el Medio Ambiente mostró su interés en el desarrollo de este nuevo Plan Quinquenal y publicó el Informe Green is Gold: The Strategy and Actions of China's Ecological Civilization (es decir: el verde es oro: la estrategia y acciones de la civilización ecológica china) en el cual analiza principalmente su dimensión ambiental. En este informe se destaca que si el país tiene éxito en su misión hacia la construcción de una "eco-civilización", casi una cuarta parte de China estaría cubierta de bosques para el año 2020, lo que significaría que la cobertura forestal del gigante asiático llegaría a más de $23 \%$. Por tanto, si China logra la consecución de estos objetivos, pasaría de ser uno de los países más contaminantes del planeta a ser una sociedad de ahorro de recursos, ambientalmente amigable que busca integrar el desarrollo ecológico con el desarrollo económico, social, cultural y político. ${ }^{35}$

\subsection{Uruguay}

Los diputados Diego Irazabal y Rodrigo Gońi presentaron, el 14 de junio de 2017, ante la Cámara de Representantes, un Proyecto de Ley sobre Economía Circular Sostenible como parte de un conjunto de proyectos con el objeto de promover e impulsar la nueva economía. En la exposición de motivos fundamentan la necesidad de su dictado, ya que el complejo problema de la generación de residuos requiere la sólida intervención del Estado a través de normas que promuevan y contribuyan a sostener el ciclo de la reducción, reutilización y reciclaje.

33 Guillermo Antuña Suárez, 13 Plan Quinquenal de la República Popular China. Octubre 2016 (Pekín: ICEX. España Exportación e Inversiones, 2016), 18-20.

34 Javier Dufour, "Multimillonario plan contra la contaminación en China", Energía y Sostenibilidad (2017), acceso el 7 de diciembre de 2018, http://www.madrimasd.org/blogs/energiasalternativas/2017/01/18/133351

35 United Nations Environment Programme, Green is Gold: The Strategy and Actions of China's Ecological Civilization (Ginebra: UNEP, 2016), 5. 
En el artículo 1 del citado proyecto, se declara de interés general la fabricación de productos que incorporen materias primas recicladas en sus procesos y en el artículo 2 se crea el Programa Nacional de Economía Circular, con la finalidad de implementar acciones que permitan: a) desarrollar protocolos para la reducción de las cantidades de desperdicios y para la utilización de materias primas recicladas en la fabricación de nuevos productos; b) crear un sistema de certificación de economía circular para organizaciones públicas y privadas, conceptos "basura cero" y regímenes de compras sustentables; c) certificar los procesos de fabricación de productos que incorporan, parcial y/o totalmente, materia prima reciclada; d) diseñar e implementar planes de capacitación y asistencia técnica; e) desarrollar líneas de investigación para la fabricación de productos innovadores elaborados con materia prima reciclada; f) desarrollar bases de datos para facilitar el análisis de ciclo de vida y alentar la creación y g) el registro de sistemas territoriales de economía circular y certificar su complementariedad productiva. Dichos sistemas deberán registrarse colectivamente en el Programa Nacional de Economía Circular.

En virtud del artículo 3 se crea el Registro Único de Emprendimientos, previa certificación de procesos y por el artículo 4, un régimen de compras estatales que beneficiará a las unidades productivas y de comercio inscriptas en el Registro Único de Emprendimientos de Economía Circular. Al respecto, conforme el artículo 5, todas las administraciones públicas estatales deberán priorizar las compras de productos en cuyo proceso de fabricación se utilicen materias primas recicladas. Asimismo se encuentran previstos beneficios tarifarios a los emprendimientos productivos, industriales y comerciales que se radiquen en una misma fracción de terreno y desarrollen acciones complementarias de gestión, reutilización y reciclaje de residuos sólidos urbanos y rurales, y que operen bajo la lógica de parques industriales (artículo 6). Como forma de sensibilizar y generar los aprendizajes que aseguren la sostenibilidad futura, a través del proyecto, la Administración Nacional de Educación Pública deberá incorporar las nociones de reducción, reutilización y reciclaje en todos sus programas educativos (artículo 7). Finalmente se crea el Fondo Nacional para la Economía Circular con la finalidad de financiar planes de economía circular (artículo 9) y un Consejo Consultivo a los efectos de asesorar en el diseño y ejecución del Plan Estratégico del Programa Nacional de Economía Circular (artículo 10). ${ }^{36}$

\subsection{Argentina}

En Argentina han comenzado recientemente los debates en pos del paradigma circular en reemplazo de la economía lineal. En todos los sectores se reconoce como indispensable la adopción de políticas que implementen el principio de la Responsabilidad Extendida del Productor. De esta forma, los fabricantes se ven incentivados a mejorar sus diseños para que los productos puedan ser recuperados y reciclados más fácilmente, disminuyendo los residuos

36 El proyecto completo se encuentra disponible en: Uruguay. Cámara de Representantes. "Proyecto de Ley Economía Circular Sostenible”, CARPETA No 2128 DE 2017. REPARTIDO No 717. Junio de 2017. 
que son descartados. Si bien Argentina fue pionera en la discusión de regulaciones, lleva más de una década debatiendo proyectos de gestión de envases. Sin embargo, el Ministerio de Ambiente de la Nación avanzó hacia "basural cero", una propuesta bastante menos ambiciosa. En el año 2004 entró en vigencia la Ley No 25.916 sobre Gestión de Residuos Domiciliarios, que establece los presupuestos mínimos de protección ambiental para la gestión integral de residuos domiciliarios de cualquier origen. Se exceptúan los que están regulados por normas específicas. Es una ley de orden público que fija el mínimo común de protección en todo el territorio nacional, pudiendo las provincias, a su vez, dictar legislación de desarrollo más estricta, elevando los niveles de protección ambiental en sus respectivas jurisdicciones. En consecuencia, cada autoridad local tiene la responsabilidad de la gestión integral de los residuos domiciliarios producidos en su jurisdicción, mediante el establecimiento de un sistema de gestión de residuos adaptados a las características y particularidades de cada una. Para ello cuentan con la posibilidad de suscribir convenios bilaterales o multilaterales, que permitan la implementación de estrategias regionales para alguna o la totalidad de las etapas de la gestión integral de los residuos domiciliarios. ${ }^{37}$

A partir de esta orientación, el Ministerio de Ambiente y Desarrollo Sustentable de la Nación, dentro del Plan Nacional de Economía Circular de Residuos, elaboró un documento denominado "Formulación de un Plan Estratégico Provincial de Gestión de Residuos hacia la Economía Circular". Consiste en un instrumento que deben desarrollar las provincias, con la debida participación de los municipios, para planificar una gestión de residuos sustentable en su territorio. El propósito de estos planes es establecer un sistema que mejore sustancialmente el manejo de los Residuos Sólidos Urbanos en el ámbito de cada provincia desde el punto de vista ambiental, económico y social. Ese plan estratégico deberá identificar lineamientos, acciones y políticas necesarias para lograr el ordenamiento y la mejora de la Gestión de Residuos Sólidos en la Provincia, contemplando el cierre de todos los basurales para el año 2025 y la tendencia a la disposición cero para el 2035. En los apartados sucesivos se describe, de manera no taxativa, los productos que deben formar parte del proceso de formulación del Proyecto, dividiéndolos en grupos: el I municipales, el II industriales, el III residuos orgánicos controlados que afectan la producción agrícola ganadera, el IV escombros y residuos de la construcción, el V vehículos fuera de uso (VFU), el VI neumáticos fuera de uso: neumático de reposición y VII basura marina. Después deberán presentar un informe sobre la gestión actual de los municipios, la presentación de los productos, la cual deberá ser revisada y aprobada por el Ministerio, la metodología y el perfil del equipo mínimo necesario para el proyecto. ${ }^{38}$

37 Véase: Argentina. Ley N²5.916. "Gestión de Residuos Domiciliarios”, Boletín Oficial de la República Argentina del 07/09/2004, n. ${ }^{\circ} 30479$.

38 Para mayor información, véase: Argentina. Ministerio de Ambiente y Desarrollo Sustentable. Plan Nacional de Economía Circular de Residuos: "Formulación de un Plan Estratégico Provincial de Gestión de Residuos hacia la Economía Circular”, acceso el 19 de diciembre de 2018, http://ambiente.gob.ar/wp-content/uploads/Plan-Estrat\%- 
La ley No 27.279 de Gestión de Envases Vacíos de Fitosanitarios entró en vigor en el mes de octubre de 2016, y fue reglamentada poco más de un año desde su publicación por el Decreto 134/2018 (publicado en el Boletín Oficial el 20 febrero de 2018). La norma establece los presupuestos mínimos de protección ambiental para la gestión diferenciada y condicionada que requieren en virtud de la toxicidad del producto que contuvieron. A esos efectos, crea un Sistema de Gestión Integral de Envases Vacíos de Fitosanitarios. La ley tiene como objetivos fundamentalmente asegurar que estos envases no sean empleados en usos que puedan implicar riesgos para la salud humana o el ambiente; mejorar la eficiencia de la gestión y dinamizar el procedimiento administrativo para el registro y autorización de comercializadores, usuarios, operadores y aplicadores. En el artículo 6 establece una jerarquía de opciones para la gestión integral, ubicando, en primer lugar, la prevención en la generación, seguida por la reutilización, después el reciclado, valorización y finalmente la disposición final. El sistema de gestión integral de envases vacíos de fitosanitarios se articula en tres etapas:

a) Del Usuario al Centro de Almacenamiento Transitorio (CAT): involucra el pasaje del envase vacío del usuario al CAT. Entonces, vaciado un envase contenedor de fitosanitarios, el usuario y aplicador serán objetivamente responsables de garantizar el procedimiento de reducción de residuos. Se establece la responsabilidad extendida y compartida con los restantes eslabones de la cadena. El usuario deberá separar los envases vacíos conforme las dos clases establecidas en el artículo 7. Posteriormente, deberán trasladarlos y entregarlos a un CAT, para lo cual no requerirán de ninguna autorización específica; el usuario tiene hasta un año de plazo a partir de la fecha de compra.

b) Del Centro de Almacenamiento Transitorio (CAT) al Operador: abarca el camino desde los CAT al operador, es decir, aquella persona natural o jurídica autorizada para modificar las características físicas y/o la composición química de cualquier envase vacío de fitosanitario. Recibidos los envases en los CAT, deberán ser clasificados y acopiados en espacios diferenciados según la tipología establecida en el artículo 7. Los envases serán derivados para su valorización o disposición final, según corresponda, mediante transportista autorizado.

c) Del Operador a la Industria: los envases vacíos procesados por el operador pasan a la industria para su posterior reinserción en un proceso productivo. Expresamente prohíbe, en el artículo 9, toda acción que implique abandono, vertido, quema y/o enterramiento de envases vacíos de fitosanitarios en todo el territorio nacional, del mismo modo que la comercialización y/o entrega de envases a personas físicas o jurídicas por fuera del sistema autorizado. Como procedimiento obligatorio para reducir los resi- 
duos de producto, se establece el lavado de envases rígidos de plaguicidas miscibles o dispersables en agua, según la norma IRAM 12069, o la que la reemplace, quedando prohibida toda carga de agua que implique contacto directo con fuentes y reservorios de agua, mediante inmersión del envase vacío de fitosanitarios. Por el artículo 24 se crea el Sistema Único de Trazabilidad, que tendrá por objetivo permitir el monitoreo permanente de los sistemas de gestión. Ante el incumplimiento de las disposiciones, la ley establece sanciones las cuales, según su gravedad, reincidencia y naturaleza, podrán ser: a) apercibimiento, b) multa pecuniaria, c) suspensión de la actividad, d) clausura temporaria o permanente, total o parcial, e) obligación de publicar la parte dispositiva de la resolución condenatoria a cargo del infractor. Las sanciones no son excluyentes y podrán aplicarse de forma concurrente. Cuando el infractor fuere una persona jurídica, sus socios y miembros serán solidariamente responsables de las sanciones establecidas, junto con sus directores, administradores y/o gerentes. ${ }^{39}$

Sin embargo, la gestión de los residuos electrónicos - RAEE — sigue siendo un proyecto. En el año 2012 perdió estado parlamentario un proyecto de ley de presupuestos mínimos para la gestión de aparatos eléctricos y electrónicos y sus residuos, que contaba con media sanción del Senado de la Nación. Actualmente, en el Congreso se están realizando varias reuniones en donde diputados oficialistas y de la oposición están discutiendo sobre la sanción de una ley nacional de responsabilidad extendida al productor que alcanzará a los residuos electrónicos — RAEE. También se está avanzando hacia una "minería urbana", la cual implica un modelo de desarrollo sostenible con inclusión social, equidad, crecimiento económico y protección ambiental.

En lo referido a las energías limpias, desde el año 2006 se encuentra vigente la Ley No 26.093 de Biocombustibles. En el año 2015 comenzó a regir la Ley No 27.191, modificando la Ley No 26.190 "Régimen de Fomento Nacional para el uso de Fuentes Renovables de Energía destinada a la Producción de Energía Eléctrica”, con el objeto de lograr para el 2018 que todos los consumidores tengan un $8 \%$ de su energía proveniente de fuentes renovables y recientemente. El Poder Ejecutivo de la Nación promulgó, a través del decreto 1075/2017, la Ley No 27424de "Régimen de Fomento a la Generación Distribuida de Energía Renovable Integrada a la Red Eléctrica Pública”. Su principal virtud, además del amplio consenso político alcanzado, es que habilita este recurso creando la figura del usuario-generador o prosumidor-consumidores a la vez que generadores de energía — que entrega electricidad limpia, producida en el mismo lugar y al mismo voltaje en que va a ser consumida, con el derecho a inyectar sus excedentes de energía eléctrica a la red reuniendo determinados requisitos técni-

39 Argentina. Ley $\mathrm{N}^{\circ}$ 27.279. "Ley de protección ambiental para la gestión de envases vacíos de fitosanitarios", Boletín oficial de la República Argentina (11 de octubre de 2016). Id SAIJ: NV15524. 
cos, tarifas de incentivos y beneficios promocionales. ${ }^{40}$ Esta ley implica un verdadero cambio de paradigma, ya que la energía no saldrá de una sola fuente para ser distribuida como sucede hasta ahora, sino que cada casa podrá ser un punto de distribución, aprovechando los recursos para generar energía in situ. Con la Ley No 27.191 solo podían generar electricidad los agentes del mercado mayorista, pero esta nueva ley es el marco regulatorio que faltaba para que todos los consumidores puedan ser generadores y permitirá que quienes instalen tecnologías de generación de energía limpia en su casa puedan no solo contribuir con la lucha contra el cambio climático, sino también ahorrar en sus facturas de luz y gas. ${ }^{41}$

No obstante, para afirmar la transición a la economía circular, todavía faltan otras leyes, por ejemplo, una ley de gestión de neumáticos usados y otra de registro de emisiones y transferencias de contaminantes, vale decir un registro información actualizada sobre sustancias químicas contaminantes o potencialmente dañinas para la salud y el ambiente.

En el ámbito local, la ciudad de Buenos Aires está migrando hacia la sostenibilidad a través de políticas públicas y el uso creciente de la tecnología, la conciencia ambiental y el consumo responsable. A este respecto, fundó el Green Economic Center (GEC) promovido por la Agencia de Protección Ambiental (APRA) del Gobierno de la Ciudad de Buenos Aires, con el objeto de fomentar un nuevo pensamiento económico siguiendo los parámetros ambientales. El Centro ha comenzado con la promoción de empleos verdes, entendiéndolo como la primera manera de involucrar a las personas con la economía circular. A través del Programa Buenos Aires Produce más Limpio busca fortalecer el paradigma ambiental en los negocios, promueve herramientas que posibiliten la interacción e integración de todos los actores para impulsar al máximo el aprovechamiento de los residuos a través del reciclado, de la reutilización y valorización. En su movimiento hacia la transformación del sector productivo en una economía sostenible, el gobierno de la Ciudad Autónoma de Buenos Aires recibió una donación de Metrópolis, ${ }^{42}$ y con esos fondos pudo desarrollar proyectos para evaluar el estado ambiental actual de sus sectores productivos, fomentar la creación de puestos de trabajo relacionados con la sostenibilidad y la coordinación entre los sectores público y privado para buscar conjuntamente soluciones circulares. Además de esta distinción se puede destacar el funcionamiento, a partir del año 2013 de la Planta de Reciclaje de tratamiento de residuos áridos. En la construcción y demolición de edificios e infraestructura, o en la rehabilitación y restauración de los mismos, se generan residuos que se denominan genéricamente áridos

40 Argentina. Ley No 27424 "Régimen de Fomento a la Generación Distribuida de Energía Renovable Integrada a la Red Eléctrica Pública”, Boletín Oficial de la República Argentina (27 de diciembre de 2017).

41 Laura Rocha, "La energía renovable, de la terraza a la red nacional", Infobae (10 de diciembre de 2017), sección sociedad, acceso el 18 de diciembre de 2017, https://www.infobae.com/sociedad/2017/12/10/la-energia-renovable-de-la-terrazaa-la-red-nacional/

42 Metrópolis es una asociación internacional líder de ciudades y regiones metropolitanas con más de un millón de habitantes. 
o "Residuos de la Construcción y Demolición" (RCD). En esa planta se reciben escombros y restos de construcción que son transformados en distintos materiales para ser reutilizados en obras civiles, viales o como capas de separación en los rellenos sanitarios. Por día ingresan a la planta alrededor de 600 camiones con material árido, producto de la actividad de unas 100 empresas y de camiones volcadores que trabajan en la Ciudad de Buenos Aires. Durante el 2014 se hicieron obras para ampliar su capacidad y, actualmente, puede tratar hasta 2400 toneladas por día, de las cuales logra recuperar un $90 \%$, que equivalen a más de 2100 toneladas/día de residuos áridos recuperados. Teniendo en cuenta que la ciudad genera por día aproximadamente 6000 toneladas de residuos, esta planta logra recuperar la fracción árida que representa un tercio del total. Asimismo, y de acuerdo con la Ley No 1854 de Gestión Integral de Residuos Sólidos Urbanos de la Ciudad conocida como "Ley Basura Cero", los generadores especiales de residuos áridos y afines deben abonar, conjuntamente con la liquidación de los derechos de delineación y construcción, sobre la base de una declaración jurada electrónica, un impuesto a la generación de residuos sólidos urbanos -RSU-. ${ }^{43}$ Dicha ley estableció un cronograma de reducción progresiva del enterramiento de residuos con plazos concretos, prohibiendo el enterramiento de residuos aprovechables y reciclables para el año 2020. También prohibió la incineración de residuos en todas sus formas, esto estará vigente al menos hasta que se llegue al objetivo de reducción del enterramiento del $75 \%$. Esta prohibición es imprescindible para la correcta aplicación del plan, ya que apunta a reducir el enterramiento de residuos para su reaprovechamiento en el circuito productivo a través de la reutilización, el reciclaje y compostaje. La ley extiende la responsabilidad de los productores, importadores y distribuidores de aquellos productos o envases de difícil o imposible reciclaje. De esta forma, quien produce artículos que contienen sustancias tóxicas, o son difíciles de aprovechar, debería hacerse cargo de su manejo luego de ser desechados. El sistema contemplado en la ley incluye la separación en origen entre residuos secos y húmedos. La ruta establecida luego de la recolección diferenciada de los residuos secos es su desvío a centros de selección, en donde se prevé que los materiales reciclables sean clasificados y acondicionados para su venta a plantas de reciclaje. Todos aquellos materiales que no se puedan reciclar se desviarán a los centros de transferencia y luego a rellenos sanitarios. Los residuos orgánicos, es decir más de la mitad de los residuos generados por la ciudad, también se separan en origen y se prevé su desvío hacia plantas de compostaje o biogás. También dispone el establecimiento de líneas de crédito para la adquisición de bienes de capital por parte de este sector. Estas medidas pretenden complementar y reforzar las disposiciones incluidas en la Ley $\mathrm{N}^{\circ} 992$ del año 2002, que incorpora a los recuperadores urbanos al servicio de higiene urbana de la ciudad y les otorga beneficios en su actividad. ${ }^{44}$

43 Los Verdes-FEP, Economía circular. Cómo mantenerse dentro de los límites ecosistémicos con equidad y satisfacción de derechos (Buenos Aires: Los Verdes, 2016), 32-35.

44 Argentina. Legislatura de la Ciudad Autónoma de Buenos Aires, "Ley Nº 1854/05 Gestión Integral de Residuos Sólidos 
Dicha ley fue modificada el 3 de mayo de 2018 por la Ley 5966. Establece un cronograma de reducción progresiva de la disposición final de residuos sólidos urbanos que conllevará a una disminución de la cantidad de desechos a ser depositados en rellenos sanitarios. Estas metas a cumplir serán de un $50 \%$ para el 2021, de un $65 \%$ para el 2025 y un $80 \%$ para el 2030. Se prohíbe para el 2028 la disposición final de materiales tanto reciclables como aprovechables, la combustión de residuos sólidos urbanos sin recuperación de energía, la contratación de servicios de tratamiento de residuos sólidos urbanos de la ciudad que tenga por objeto la combustión sin recuperación de energía en otras jurisdicciones y el tratamiento térmico de materiales reciclables o aprovechables provenientes de todo circuito de recolección diferenciada. También habilita la transformación y valorización de la fracción de residuos sólidos urbanos húmedos, mediante técnicas de combustión con recuperación energética, previo tratamiento en planta de separación selectiva. A diferencia de la anterior, esta modificación promueve el aprovechamiento de los residuos sólidos urbanos, incluyendo la combustión con recuperación energética, cuyo tratamiento, dejando a salvo la protección de la salud de las personas y del ambiente, deberá cumplir con las siguientes condiciones: a) utilizar métodos o tecnologías que aseguren el cumplimiento de los estándares de eficiencia energética definidos en la Directiva 2008/98/CE del Parlamento Europeo y del Consejo así como sus actualizaciones posteriores, b) los límites para las emisiones a la atmósfera producto de la combustión de residuos no podrán superar los límites establecidos en el Anexo VI, Parte 3, de la Directiva 2010/75/UE del Parlamento Europeo y del Consejo, y c) la gestión de los residuos resultantes de la combustión debe realizarse según las normas vigentes para el tratamiento de residuos, en particular las cenizas volantes que deben ser consideradas como residuos peligrosos. Finalmente, crea el Sistema de Información Pública del Sector de la Valorización Energética de Residuos (SIPSVER), a los efectos del monitoreo continuo y permanente de las emisiones en la atmósfera, en el suelo y en las aguas superficiales y subterráneas que resulten de las actividades de combustión con recuperación energética. ${ }^{45}$

Sin embargo, el 27 de junio de 2018, la Dra. Elena Liberatori, Jueza del Juzgado de $1^{\circ}$ en lo Contencioso y Administrativo de la Ciudad, en los autos caratulados "Federación de Cooperativas de Reciclado Limitada y otros contra GCBA y otros sobre Amparo-Ambiental”, Expte. No EXP 12519-2018/0, ordenó disponer la suspensión inmediata de los efectos de la Ley $\mathrm{N}^{\circ} 5.966$, es decir, suspende la autorización legal para que el Gobierno de la Ciudad pueda incinerar residuos, por cuestiones de forma y procedimentales que fundamentalmente se relaciona con el procedimiento de doble lectura para temas ambientales que no se respetó.

Urbanos", Boletín Oficial de la Ciudad Autónoma de Buenos Aires, n. 2357.

45 Argentina. Legislatura de la Ciudad Autónoma de Buenos Aires, "Ley 5966. Se modifica la Ley No 1854 - Basura cero", Boletin Oficial de la Ciudad Autónoma de Buenos Aires (23/05/2018). 


\section{Normativa voluntaria}

En mayo del año 2017, The British Standards Institution (BSI $)^{46}$ publicó la norma voluntaria para la Economía Circular denominada BS 8001:2017 Framework for implementing the principles of the circular economy in organizations, vale decir "BS 8001: 2017: Marco para la aplicación de los principios de la economía circular en las organizaciones”. La finalidad de la norma es proporcionar un marco para la aplicación de esta iniciativa en las organizaciones. Es una guía para que las organizaciones logren pasar las diferentes etapas de la implementación de los postulados de la economía circular. El instrumento es la primera norma voluntaria sobre este tipo de economía, tanto en el Reino Unido como en el resto de los países y a nivel de normalización internacional. La piedra angular del estándar es la aplicación práctica de los principios de la economía circular, vale decir, el pensamiento sistémico (las organizaciones adoptan un enfoque holístico para entender cómo las decisiones y actividades individuales interactúan dentro del sistema más amplio); la innovación (innovar continuamente para crear valor comercial a través de la gestión sostenible de los recursos tanto en productos como en servicios); la gestión (gestionar los impactos directos e indirectos de sus decisiones y actividades); colaboración (las organizaciones colaboran interna y externamente mediante acuerdos para crear valor comercial mutuo); optimización del valor (mantener en todo momento los productos, componentes y materiales en su máximo valor y utilidad) y transparencia. Es importante destacar que la norma no pretende ser prescriptiva o certificable; está destinada a ser utilizada con flexibilidad por aquellos que la adopten —independientemente del tamańo, sector, tipo o ubicación de la organización y ha sido escrita de manera que pueda ser utilizada en cualquier parte del mundo. Será útil para aquellos con diferentes niveles de conocimiento y comprensión de la economía circular y es adecuada en la aplicación de los principios de la economía circular para las organizaciones, tanto en una etapa de transición incipiente o más avanzada. Para apoyar el marco, la BS 8001:2017 proporciona orientación sobre los temas específicos que rodean la transición a un modelo circular. Durante esa fase piloto se consultó a una variedad de empresas y organizaciones de diferentes sectores y tamańos, tanto en el Reino Unido como en el extranjero, para asegurar que la norma satisfacía sus necesidades de orientación práctica y recomendaciones. ${ }^{47}$

46 La British Standards Institution, cuyas siglas corresponden a BSI, es un organismo nacional de normalización sin ánimo de lucro reconocido del Reino Unido. Entre sus actividades principales se incluyen la normalización, evaluación de sistemas, certificación de productos, formación y servicios de asesoramiento.

47 British Standards Institution. BSI, Executive Briefing on BS 8001 Framework for implementing the principles of the circular economy in organizations - Guide (Londres: BSI, 2017). 


\section{CONCLUSIÓN}

En el desarrollo del artículo se han analizado las recientes legislaciones que avanzan hacia un cambio de paradigma: de la economía lineal bajo el lema "extraer-fabricar-tirar", a la economía circular basada en "refabricar, reacondicionar y reciclar". El modelo lineal de producción vigente durante los últimos 50 años ocasionó el agotamiento de los recursos naturales, permitiendo la pérdida generalizada de los ecosistemas y la indiferencia frente a la extrema pobreza de muchas personas que dependen directamente de ellos. Por tanto, desde la comunidad científica, la sociedad civil, las empresas y los Estados avanzan hacia un nuevo sistema económico ecológicamente racional, ecoeficiente e inclusivo, actuando sobre las causas fundamentales de los desequilibrios. Sin embargo, para iniciar la transición hacia la economía circular es imprescindible la sanción de un marco normativo regulador de la responsabilidad extendida del productor, de la gestión de los residuos plásticos, eléctricos y electrónicos, que obligue al fabricante y productor a incorporar siempre una parte de material reciclado en cada producto. Además, es necesario formular políticas públicas que fomenten la economía colaborativa y que penalicen la linealidad en los procesos productivos. Sin olvidarse del etiquetado ecológico, el ecodiseño, la construcción de edificios sostenibles así como resulta fundamental trabajar en la educación ambiental, creativa y emprendedora para que suceda el cambio. En esta línea de trabajo, el Paquete de Acción de Economía Circular de la Unión Europea del año 2015 inició el camino hacia la economía circular, pero China ya hace años que viene elaborando normativas para implementar este modelo en aras del crecimiento sostenible y que aporte beneficios sociales, económicos y ambientales. En el año 2007, este país asiático propuso por primera vez la construcción de una civilización ecológica, incorporando así el concepto de desarrollo sostenible al contexto de la civilización humana y después de 10 años, ha avanzado considerablemente en sus acciones, así como en la defensa de una civilización ecológica. ${ }^{48}$

Uruguay cuenta ya con un proyecto de ley sobre Economía Circular Sostenible y en Argentina, a partir del año 2017, se vislumbran avances hacia la circularidad. Por un lado, la posibilidad de crear un impuesto al carbono es una de las discusiones pendientes en la agenda política, aunque se trabaja con un borrador en el Congreso. Se encuentra en discusión la sanción de una ley nacional de responsabilidad extendida al productor que alcanzará a los residuos electrónicos — RAEE. También se está avanzando hacia una "minería urbana", la cual implica un modelo de desarrollo sostenible con inclusión social, equidad, crecimiento económico y protección ambiental.

Sobre la base de lo reciente de la normativa analizada, resulta apresurado emitir juicio acerca de su efectividad y eficacia para el cumplimiento de los objetivos propuestos.

48 Zhang Huiyuan, "Civilización ecológica y desarrollo sostenible”, China Hoy (5 de diciembre de 2017), sección economía, acceso el 3 de febrero de 2019, http://spanish.chinatoday.com.cn/eco/analys/content/2017-12/05/content_750847.htm 


\section{REFERENCIAS}

- Antuña Suárez, Guillermo. $13^{\circ}$ Plan Quinquenal de la República Popular China. Octubre 2016. Pekín: ICEX. España Exportación e Inversiones, 2016.

- Argentina. Legislatura de la Ciudad Autónoma de Buenos Aires. "Ley N 1854/05 Gestión Integral de Residuos Sólidos Urbanos". Boletín Oficial de la Ciudad Autónoma de Buenos Aires, n. 2357.

- Argentina. Legislatura de la Ciudad Autónoma de Buenos Aires. "Ley 5966. Se modifica la Ley No 1854 - Basura cero". Boletín Oficial de la Ciudad Autónoma de Buenos Aires $(23 / 05 / 2018)$.

- Argentina. Ley N 25.916. "Gestión de Residuos Domiciliarios”. Boletín Oficial de la República Argentina del 07/09/2004, n. ${ }^{\circ} 30479$.

- Argentina. Ley No 27.279. "Ley de protección ambiental para la gestión de envases vacíos de fitosanitarios". Boletín oficial de la República Argentina (11 de octubre de 2016). Id SAIJ: NV15524.

- Argentina: Ley No 27424 "Régimen de Fomento a la Generación Distribuida de Energía Renovable Integrada a la Red Eléctrica Pública”. Boletín Oficial de la República Argentina (27 de diciembre de 2017).

- Argentina. Ministerio de Ambiente y Desarrollo Sustentable. Plan Nacional de Economía Circular de Residuos: "Formulación de un Plan Estratégico Provincial de Gestión de Residuos hacia la Economía Circular”. Acceso el 19 de diciembre de 2018. http://ambiente.gob.ar/wp-content/uploads/Plan-Estrat\%C3\%A9gico-Provincial-PEPpara-la-Gesti\%C3\%B3n-Integral-de-Residuos-S\%C3\%B3lidos-Urbanos-hacia-unaEconom\%C3\%ADa-Circular.pdf

- Avilés Pozo, Alicia. "Castilla - La Mancha tomará la delantera con la primera Ley de Economía Circular de España”. eldiario.es Castilla-La Mancha, 1 de noviembre de 2017. Acceso el 1 de febrero de 2019. http://www.eldiario.es/clm/Castilla-La-Mancha-Economia-Circular-Espana_0_703429894.html

- British Standards Institution. BSI. Executive Briefing on BS 8001 Framework for implementing the principles of the circular economy in organizations - Guide. Londres: BSI, 2017.

- "China quiere ponerse al nivel de la UE en desarrollo de la economía circular". La Vanguardia, 23 de noviembre de 2016. Acceso el 29 de mayo de 2018.

http:/www.lavanguardia.com/vida/20161123/412109862646/china-quiere-ponerse-alnivel-de-la-ue-en-desarrollo-de-la-economia-circular.html 
- Comisión Europea. "Comunicación de la Comisión al Parlamento Europeo, al Consejo, al Comité Económico y Social Europeo y al Comité de las Regiones. Cerrar el círculo: un plan de acción de la UE para la economía circular". COM (2015) 614 final. Bruselas: Comisión Europea, 2015.

- Comisión Europea. "Comunicación de la Comisión al Parlamento Europeo, al Consejo, al Comité Económico y Social Europeo y al Comité de las Regiones. Sobre un marco de seguimiento para la economía circular”. COM (2018) 29 final. Estrasburgo: Comisión Europea, 2018.

- Comisión Europea. "Comunicado de prensa. Cerrar el círculo: la Comisión adopta un ambicioso paquete de nuevas medidas sobre la economía circular para impulsar la competitividad, crear empleo y generar crecimiento sostenible". IP/15/6203. Bruselas: Comisión Europea, 2015.

- Comisión Europea. "Comunicado de prensa. Economía circular: La Comisión cumple sus promesas, ofrece orientaciones sobre la valorización energética a partir de residuos y trabaja con el BEI para impulsar la inversión”. IP/17/104. Bruselas: Comisión Europea, 2017.

- Comité Económico y Social Europeo. “Dictamen del Comité Económico y Social Europeo Comunicación de la Comisión al Parlamento Europeo, al Consejo, al Comité Económico y Social Europeo y al Comité de las Regiones 'El papel de la transformación de los residuos en energía”". Diario Oficial de la Unión Europea. 13 de octubre de 2017. C 345/102-109 [COM (2017) 34 final].

- Comité Europeo de las Regiones. "Dictamen: El papel de la transformación de los residuos en energía en la economía circular”. COR-2017-01982-00-00-AC-TRA.

- Comunidad de Castilla y León. Consejería de Economía y Hacienda. "ACUERDO 2/2018, de 18 de enero, de la Junta de Castilla y León, por el que se aprueba la Estrategia de Eficiencia Energética de Castilla y León 2020”. Boletín Oficial de Castilla y León, n. 16. 23 de enero de 2018.

- Dufour, Javier. "Multimillonario plan contra la contaminación en China”. Energía y sostenibilidad. 2017. Acceso el 7 de diciembre de 2018. http://www.madrimasd.org/blogs/energiasalternativas/2017/01/18/133351

- España. Ministerio de Agricultura y Pesca, Alimentación y Medio Ambiente. "Pacto por una economía circular: El compromiso de los agentes económicos y sociales 2018-2020". Mapama (2017). Acceso el 8 de abril de 2018. http:/www.mapama.gob.es/directo/ PactoEconomiaCircular.pdf 
- España. Ministerio de la Presidencia y para las Administraciones Territoriales. "Real Decreto 6/2018, de 12 de enero, por el que se crea la Comisión Interministerial para la incorporación de criterios ecológicos en la contratación pública”. Boletín Oficial del Estado, n. ${ }^{\circ} 19$, sec. 1 (22 de enero de 2018).

- Francia. Ayuntamiento de París, Call of cities for circular economy. París, 2015. Acceso el 8 de noviembre de 2018. http://www.acrplus.org/images/news/20150915-EtatsGenerauxcall_of_cities_for_circular_economy.pdf

- Fresneda, Carlos. "Las siete 'R' de la ciudad circular". El Mundo. España (2017). Acceso el 15 de diciembre de 2018. https:/www.elmundo.es/ciencia-y-salud/ ciencia/2017/07/31/597e21d3268e3eea578b457b.html

- Fundación Cotec. Situación y evolución de la economía circular en España. Madrid: Fundación Cotec, 2017.

- Fundación para la Economía Circular. "España aprueba el Real Decreto sobre reducción del consumo de las bolsas de plástico". Boletín De la cuna a la cuna (2018). Acceso el 4 de junio de 2018. http://economiacircular.org/NL/nt/210518/noticia3.html

- García García, Sara. "Economía Circular: La Unión Europea impulsa reformas sobre la base de un tema crucial, la gestión de residuos, con el fin de alcanzar mejoras económicas y medioambientales". Revista Actualidad Juridica Ambiental, n. ${ }^{\circ} 57$ (2016): 1-11. ISSN: 1989-5666 NIPO: 721-15-001-4.

- Govern de la Generalitat de Catalunya "Impuls a l'EconomiaVerda I a l'Economia Circular". Diari Oficial de la Generalitat de Catalunya. n. ${ }^{\circ} 6881,28$ de mayo de 2015. CVE-DOGC-A-15146102-2015.

- Hernández, Leticia y José Luis Ruiz Galán. “Nueva Ley de Economía Circular”. Roca Junyent Shanghai Office (2008). Acceso el 14 de diciembre de 2018.

https://www.casaasia.es/pdf/220954813PM1233593293716.pdf

- Huiyuan, Zhang. "Civilización ecológica y desarrollo sostenible”. China Hoy (5 de diciembre de 2017). Sección economía. Acceso el 3 de febrero de 2019. http://spanish.chinatoday.com.cn/eco/analys/content/2017-12/05/content_750847.htm

- Junta de Extremadura. "Marco Regional de Impulso a la Economía Verde y Circular en Extremadura”. Extremadura (2017). Acceso el 3 de diciembre de 2018. http:// extremadura2030.com/wp-content/uploads/2017/03/marco_070617_v.f_sin-anexos.pdf

- Los Verdes- FEP. Economía circular. Cómo mantenerse dentro de los límites ecosistémicos con equidad y satisfacción de derechos. Buenos Aires: Los Verdes, 2016. 
- Martín, Laura. "Europa da carpetazo a la economía de 'usar y tirar' y apuesta por la economía circular". Compromiso Empresarial (2016). Acceso el 15 de diciembre de 2018. http:// www.compromisoempresarial.com/rsc/2016/01/europa-da-carpetazo-a-la-economia-deusar-y-tirar-y-apuesta-por-la-economia-circular/

- Martínez, Adriana Norma y Adriana Margarita, Porcelli. "El desafío del cambio económico: la economía circular y su excepción en las diferentes legislaciones y en la normativa voluntaria”. Pensar en Derecho, n. ${ }^{\circ}$ 13, año V (2018): 129-181. ISSN 2314-0194.

- Martínez, Adriana Norma y Adriana Margarita, Porcelli. "Estudio sobre la economía circular como una alternativa sustentable frente al ocaso de la economía tradicional (primera parte)". Lex 22, 16, año XVI (2018): 301-334. ISSN 2313-1861.

https://doi.org/10.21503/lex.v16i22.1659

- Mathews, John y Hao Tan. "Lessons from China". Nature, n. ${ }^{\circ} 531$ (2016): 440-443. https://doi.org/10.1038/531440a

PMid:27008954

- Muznik, Sara. "Deliver or pay, or how waste incineration causes recycling to slow down". Zero Waste Europe (2017). Acceso el 16 de diciembre de 2018. https://zerowasteeurope. eu/2017/10/deliver-pay-waste-incineration-causes-recycling-slow/

- Parra Pérez, Águeda. "XIII Plan Quinquenal de China: desafíos geopolíticos para la gobernanza mundial". Instituto Español de Estudios Estratégicos (2016). Acceso el 9 de diciembre de 2018. http://www.ieee.es/Galerias/fichero/docs_opinion/2016/ DIEEEO96-2016_PlanQuinquenal_China_AguedaParra.pdf

- Pérez de las Heras, Beatriz. "La gestión eficiente de recursos en la Unión Europea: alcance e impacto de la normativa europea para una economía más sostenible y circular". Revista de Derecho Comunitario Europeo, n. ${ }^{\circ} 55$ (2016): 781-817.

https://doi.org/10.18042/cepc/rdce.55.01

- Real Ferrer, Gabriel. "Residuos y sostenibilidad. El modelo europeo". Revista Aranzadi de Derecho Ambiental, n. 35 (2016): 57-87.

- Rocha, Laura. "La energía renovable, de la terraza a la red nacional". Infobae (10 de diciembre de 2017). Sección sociedad. Acceso el 18 de diciembre de 2017.

https://www.infobae.com/sociedad/2017/12/10/la-energia-renovable-de-la-terraza-a-lared-nacional/

- Sociedad Pública de Gestión Ambiental. Iniciativas empresariales de economía circular en el País Vasco. Descripción de 36 proyectos. Bilbao: Sociedad Pública de Gestión Ambiental, 2017. 
- "Sostener el impulso de la transición a la economía circular". Revista Medio Ambiente para los Europeos, n. ${ }^{\circ} 64$ (2017).

- United Nations Environment Programme. "Forests to cover one quarter of China in country's bid to build eco-civilization". UNEP (2016). Acceso el 7 de agosto de 2018. https://www.unenvironment.org/news-and-stories/news/forests-cover-one-quarter-chinacountrys-bid-build-eco-civilization

- United Nations Environment Programme. Green is Gold: The Strategy and Actions of China's Ecological Civilization. Ginebra: UNEP, 2016.

- Uruguay. Cámara de Representantes. "Proyecto de Ley Economía Circular Sostenible". CARPETA No 2128 DE 2017. REPARTIDO No 717. Junio de 2017.

RECIBIDO: $16 / 02 / 2019$

APROBADO: 27/05/2019 


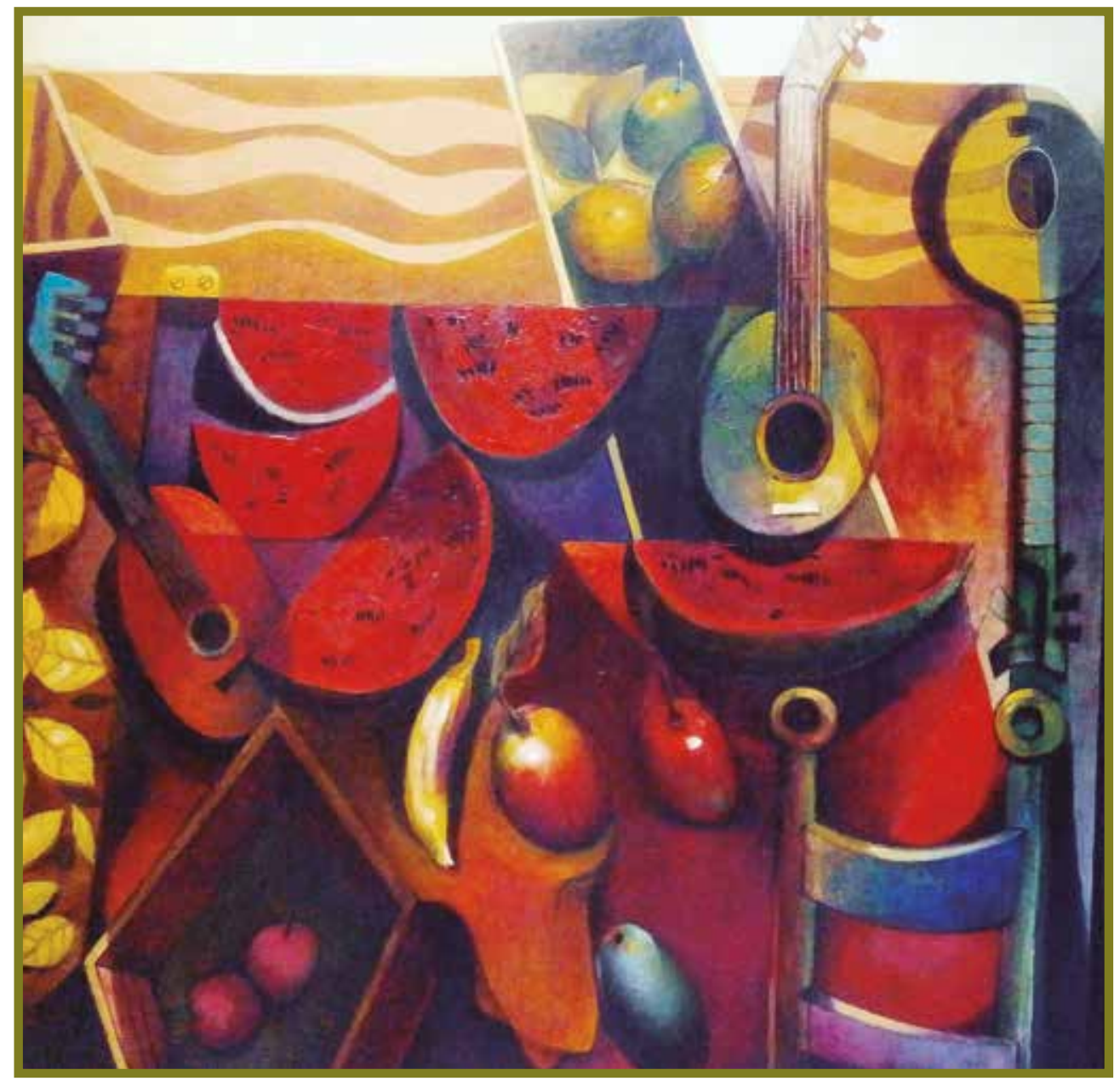

Bodegón. Óleo 110 x $110 \mathrm{~cm}$.

Agustín Aquino Mejías (pintor peruano). 